Cochrane Database of Systematic Reviews

\title{
Plasma exchange for Guillain-Barré syndrome (Review)
}

Chevret S, Hughes RAC, Annane D

Chevret S, Hughes RAC, Annane D.

Plasma exchange for Guillain-Barré syndrome.

Cochrane Database of Systematic Reviews 2017, Issue 2. Art. No.: CD001798.

DOI: 10.1002/14651858.CD001798.pub3.

www.cochranelibrary.com 
TABLE OF CONTENTS

ABSTRACT

PLAIN LANGUAGE SUMMARY

SUMMARY OF FINDINGS

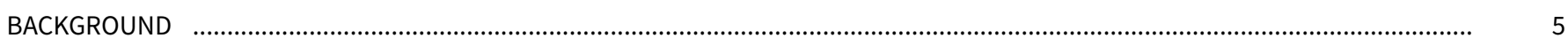

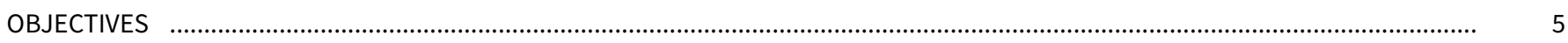

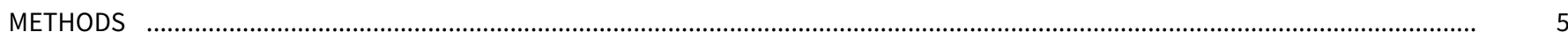

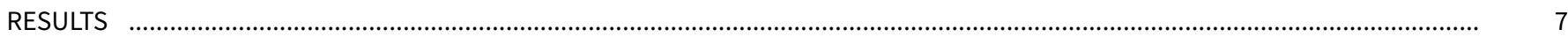

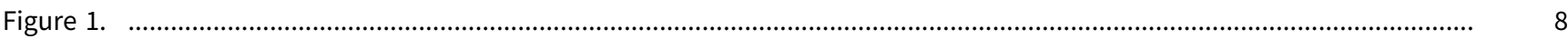

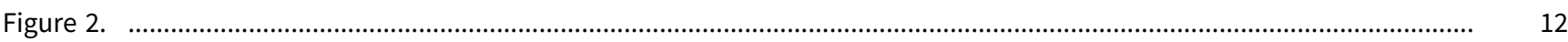

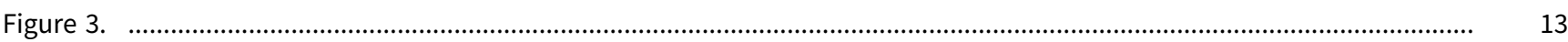

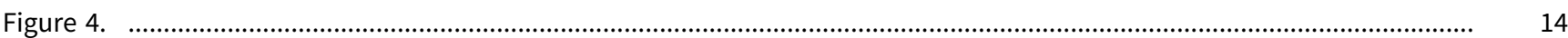

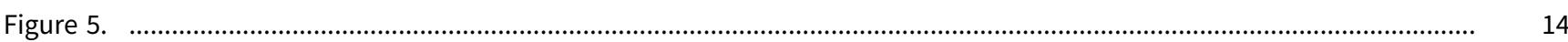

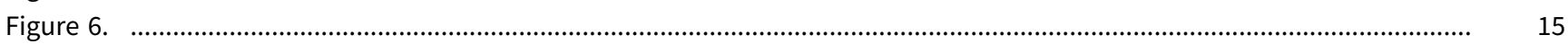

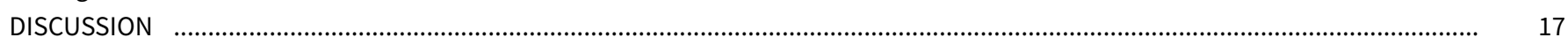

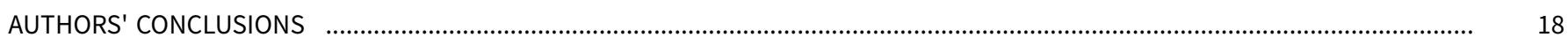

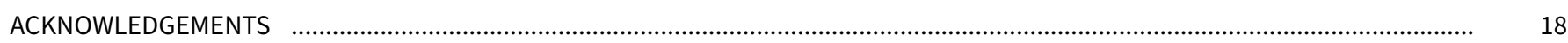

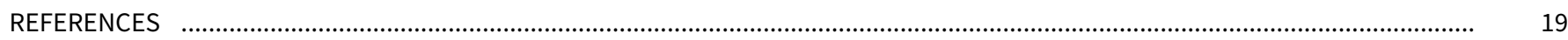

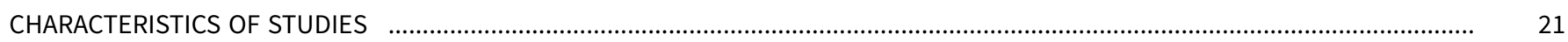

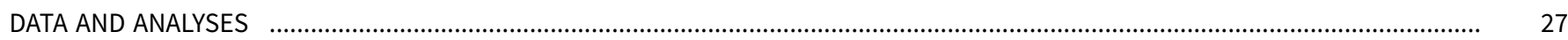

Analysis 1.1. Comparison 1 Plasma exchange compared to sham exchange or supportive treatment for Guillain-Barré 28 syndrome: four-week end points, Outcome 1 Walking with aid after 4 weeks.

Analysis 1.2. Comparison 1 Plasma exchange compared to sham exchange or supportive treatment for Guillain-Barré syndrome: four-week end points, Outcome 2 Improvement by 1 grade after 4 weeks.

Analysis 1.3. Comparison 1 Plasma exchange compared to sham exchange or supportive treatment for Guillain-Barré syndrome: four-week end points, Outcome 3 Mean disability grade improvement after 4 weeks.

Analysis 1.4. Comparison 1 Plasma exchange compared to sham exchange or supportive treatment for Guillain-Barré syndrome: four-week end points, Outcome 4 Walking without aid after 4 weeks.

Analysis 1.5. Comparison 1 Plasma exchange compared to sham exchange or supportive treatment for Guillain-Barré syndrome: four-week end points, Outcome 5 Mechanically ventilated after 4 weeks.

Analysis 1.6. Comparison 1 Plasma exchange compared to sham exchange or supportive treatment for Guillain-Barré syndrome: four-week end points, Outcome 6 Duration of mechanical ventilation.

Analysis 2.1. Comparison 2 Plasma exchange compared to sham exchange or supportive treatment for Guillain-Barré syndrome: one-year end points, Outcome 1 Full muscle strength recovery at 1 year.

Analysis 2.2. Comparison 2 Plasma exchange compared to sham exchange or supportive treatment for Guillain-Barré syndrome: one-year end points, Outcome 2 Deaths.

Analysis 2.3. Comparison 2 Plasma exchange compared to sham exchange or supportive treatment for Guillain-Barré syndrome: one-year end points, Outcome 3 Severe motor sequelae.

Analysis 2.4. Comparison 2 Plasma exchange compared to sham exchange or supportive treatment for Guillain-Barré syndrome: one-year end points, Outcome 4 Relapses during follow-up period.

Analysis 3.1. Comparison 3 Plasma exchange compared to sham exchange or supportive treatment for Guillain-Barré syndrome: complications during hospital stay, Outcome 1 Severe infection.

Analysis 3.2. Comparison 3 Plasma exchange compared to sham exchange or supportive treatment for Guillain-Barré syndrome: complications during hospital stay, Outcome 2 Blood pressure instability.

Analysis 3.3. Comparison 3 Plasma exchange compared to sham exchange or supportive treatment for Guillain-Barré syndrome: complications during hospital stay, Outcome 3 Cardiac arrhythmias.

Analysis 3.4. Comparison 3 Plasma exchange compared to sham exchange or supportive treatment for Guillain-Barré syndrome: complications during hospital stay, Outcome 4 Pulmonary embolus.

APPENDICES

WHAT'S NEW

HISTORY

CONTRIBUTIONS OF AUTHORS

DECLARATIONS OF INTEREST

SOURCES OF SUPPORT

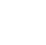

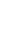

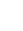

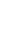

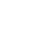

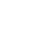

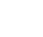

4

5
(1) 19 
[Intervention Review]

\section{Plasma exchange for Guillain-Barré syndrome}

Sylvie Chevret ${ }^{1}$, Richard AC Hughes ${ }^{2}$, Djillali Annane ${ }^{3}$

1Departement de Biostatistique et Informatique Médicale, Hôpital Saint Louis, 75475 Paris, France. 2MRC Centre for Neuromuscular Diseases, National Hospital for Neurology and Neurosurgery, London, UK. ${ }^{3}$ Critical Care Department, Hôpital Raymond Poincaré, Assistance Publique - Hôpitaux de Paris, Garches, France

Contact: Djillali Annane, Critical Care Department, Hôpital Raymond Poincaré, Assistance Publique - Hôpitaux de Paris, 104. Boulevard Raymond Poincaré, Garches, Ile de France, 92380, France. djillali.annane@rpc.ap-hop-paris.fr.

Editorial group: Cochrane Neuromuscular Group.

Publication status and date: Edited (no change to conclusions), published in Issue 3, 2017.

Citation: Chevret S, Hughes RAC, Annane D. Plasma exchange for Guillain-Barré syndrome. Cochrane Database of Systematic Reviews 2017, Issue 2. Art. No.: CD001798. DOI: 10.1002/14651858.CD001798.pub3.

Copyright @ 2017 The Cochrane Collaboration. Published by John Wiley \& Sons, Ltd.

\section{A B S T R A C T}

\section{Background}

Guillain-Barré syndrome (GBS) is an acute paralysing disease caused by peripheral nerve inflammation. This is an update of a review first published in 2001 and last updated in 2012.

\section{Objectives}

To assess the effects of plasma exchange for treating GBS.

\section{Search methods}

On 18 January 2016 we searched the Cochrane Neuromuscular Specialised Register, CENTRAL, MEDLINE, and Embase. We also searched clinical trials registries.

\section{Selection criteria}

Randomised and quasi-randomised trials of plasma exchange versus sham exchange or supportive treatment, or comparing different regimens or techniques of plasma exchange.

\section{Data collection and analysis}

We followed standard Cochrane methodology.

\section{Main results}

In the first version of this review there were six eligible trials concerning 649 participants comparing plasma exchange with supportive treatment. No new eligible trials have been identified in subsequent updates. Two other studies compared different numbers of plasma exchanges. Overall the included trials had a moderate risk of bias (in general, the studies were at low risk but all had a high risk of bias from lack of blinding).

In one trial with 220 severely affected participants, the median time to recover walking with aid was significantly shorter with plasma exchange (30 days) than without plasma exchange (44 days). In another trial with 91 mildly affected participants, the median time to onset of motor recovery was significantly shorter with plasma exchange (six days) than without plasma exchange (10 days). After four weeks, moderate-quality evidence from the combined data of three trials accounting for a total of 349 patients showed that plasma exchange significantly increased the proportion of patients who recovered the ability to walk with assistance (risk ratio (RR) $1.60,95 \%$ confidence interval (Cl) 1.19 to 2.15$)$. 
In five trials with 623 participants in total, moderate-quality evidence showed that the RR for improvement by one or more disability grades after four weeks was $1.64(95 \% \mathrm{Cl} 1.37$ to 1.96$)$ times greater with plasma exchange. Participants treated with plasma exchange also fared better, according to moderate-quality evidence, in time to recover walking without aid (three trials with 349 participants; RR 1.72, 95\% $\mathrm{Cl}$ 1.06 to 2.79 ) and requirement for artificial ventilation (five trials with 623 participants; RR $0.53,95 \% \mathrm{Cl} 0.39$ to 0.74 ). More participants had relapses by the end of follow-up in the plasma exchange group than in the control group (six trials with 649 participants; RR 2.89, 95\% $\mathrm{Cl} 1.05$ to 7.93; moderate-quality evidence). Despite this, according to moderate-quality evidence, the likelihood of full muscle strength recovery at one year was greater with plasma exchange than without plasma exchange (five trials with 404 participants; $\mathrm{RR} 1.24,95 \% \mathrm{Cl}$ 1.07 to 1.45), and the likelihood of severe motor sequelae was less (six trials with 649 participants; RR $0.65,95 \% \mathrm{Cl} 0.44$ to 0.96 ). Highquality evidence from six trials with 649 participants could not confirm or refute a lower risk of death following plasma exchange compared to control (RR $0.86,95 \% \mathrm{Cl} 0.45$ to 1.65 ).

Three trials $(\mathrm{N}=556)$ provided details of serious adverse events during the hospital stay; combined analyses found no increase in serious infectious events compared to the control group (RR 0.91, 95\% Cl 0.73 to 1.13), nor were there clear differences in blood pressure instability, cardiac arrhythmias or pulmonary emboli.

\section{Authors' conclusions}

Moderate-quality evidence shows significantly more improvement with plasma exchange than with supportive care alone in adults with Guillain-Barré syndrome, without a significant increase in serious adverse events. According to moderate-quality evidence, there was a small but significant increase in the risk of relapse during the first six to 12 months after onset in people treated with plasma exchange compared with those who were not treated. Despite this, after one year, full recovery of muscle strength was more likely and severe residual weakness less likely with plasma exchange.

\section{PLAIN LANGUAGE SUMMARY}

\section{Plasma exchange for Guillain-Barré syndrome}

\section{Review question}

We reviewed the evidence about the effect of plasma exchange in people with Guillain-Barré syndrome (GBS).

\section{Background}

GBS is a rare, serious disease in which the peripheral nerves (nerves outside the central nervous system) become inflamed. The condition causes paralysis and sensory disturbance. Many people who develop GBS have had a recent chest or intestinal infection that may cause an allergic attack on the nerves. Antibodies against the infection also target the nerves and cause GBS. Plasma exchange removes soluble factors including antibodies from the blood and is used as treatment. Plasma exchange replaces the person's own plasma with an artificial plasma substitute, usually an albumin solution.

\section{Study characteristics}

We carried out a wide search of medical databases for trials in which participants were randomly assigned to plasma exchange or no treatment except supportive care. We found six trials, which included 649 participants in total. All six trials compared plasma exchange with supportive treatment. All were at low risk of bias, except that participants and their carers were aware of the treatment given (they were not blinded). Two additional studies compared different numbers of plasma exchange and could not be included in the analysis but are discussed.

\section{Key results and quality of the evidence}

Plasma exchange speeded improvement from GBS. It did not cause harm apart from being followed by a probable slight increase in risk of relapse. Despite this, plasma exchange probably increases the chance of complete muscle strength recovery after one year. No new trials have been done since the first publication of this review in 2001. However trials have been done comparing plasma exchange with intravenous infusion of human immune globulin (the antibody portion of plasma). These trials are included in another Cochrane review and show the effects of the two treatments are similar.

The evidence is up to date to 18 January 2016. 


\begin{tabular}{|c|c|c|c|c|c|c|}
\hline \multicolumn{7}{|c|}{$\begin{array}{l}\text { S U M M A R Y O F F I N D I N G S } \\
\text { Summary of findings for the main comparison. Plasma exchange compared to sham exchange or supportive treatment for Guillain-Barré syndrome }\end{array}$} \\
\hline \multicolumn{7}{|c|}{ Plasma exchange compared to sham exchange or supportive treatment for Guillain-Barré syndrome } \\
\hline \multicolumn{7}{|c|}{$\begin{array}{l}\text { Patient or population: people with Guillain-Barré syndrome } \\
\text { Settings: hospital } \\
\text { Intervention: plasma exchange } \\
\text { Comparison: sham exchange or supportive treatment }\end{array}$} \\
\hline \multirow[t]{3}{*}{ Outcomes } & \multicolumn{2}{|c|}{ Illustrative comparative risks ${ }^{\star}(95 \% \mathrm{Cl})$} & \multirow{3}{*}{$\begin{array}{l}\text { Relative effect } \\
(95 \% \mathrm{CI})\end{array}$} & \multirow{3}{*}{$\begin{array}{l}\text { No of Partici- } \\
\text { pants } \\
\text { (studies) }\end{array}$} & \multirow{3}{*}{$\begin{array}{l}\text { Quality of the } \\
\text { evidence } \\
\text { (GRADE) }\end{array}$} & \multirow[t]{3}{*}{ Comments } \\
\hline & Assumed risk & Corresponding risk & & & & \\
\hline & $\begin{array}{l}\text { Sham exchan } \\
\text { supportive tr } \\
\text { ment }\end{array}$ & Plasma exchange & & & & \\
\hline \multirow{2}{*}{$\begin{array}{l}\text { Walking with aid at } 4 \text { weeks } \\
\text { Follow-up: mean } 4 \text { weeks }\end{array}$} & \multicolumn{2}{|c|}{ Study population } & \multirow{2}{*}{$\begin{array}{l}\text { RR } 1.60 \\
\text { (1.19 to } 2.15)\end{array}$} & \multirow{2}{*}{$\begin{array}{l}349 \\
\text { (3 studies) }\end{array}$} & \multirow{2}{*}{$\begin{array}{l}\oplus \oplus \oplus \ominus \\
\text { moderate } 1\end{array}$} & \\
\hline & 266 per 1000 & $\begin{array}{l}\mathbf{4 2 5} \text { per } \mathbf{1 0 0 0} \\
(316 \text { to } 571)\end{array}$ & & & & \\
\hline \multirow{2}{*}{$\begin{array}{l}\text { Dependency on a ventilator at } 4 \\
\text { weeks } \\
\text { Follow-up: mean } 4 \text { weeks }\end{array}$} & \multicolumn{2}{|c|}{ Study population } & \multirow{2}{*}{$\begin{array}{l}\mathbf{R R} \mathbf{0 . 5 3} \\
(0.39 \text { to } 0.74)\end{array}$} & \multirow{2}{*}{$\begin{array}{l}623 \\
\text { (5 studies) }\end{array}$} & \multirow{2}{*}{$\begin{array}{l}\oplus \oplus \oplus \ominus \\
\text { moderate } 1\end{array}$} & \multirow{2}{*}{$\begin{array}{l}\text { Plasma exchange ther- } \\
\text { apy reduced the risk of } \\
\text { being ventilator depen- } \\
\text { dent at } 4 \text { weeks }\end{array}$} \\
\hline & 270 per 1000 & $\begin{array}{l}\mathbf{1 4 3} \text { per } 1000 \\
(105 \text { to } 200)\end{array}$ & & & & \\
\hline \multirow{2}{*}{$\begin{array}{l}\text { Full muscle strength recovery } \\
\text { at } 1 \text { year } \\
\text { Follow-up: mean } 1 \text { year }\end{array}$} & \multicolumn{2}{|c|}{ Study population } & \multirow{2}{*}{$\begin{array}{l}\text { RR } 1.24 \\
(1.07 \text { to } 1.45)\end{array}$} & \multirow{2}{*}{$\begin{array}{l}404 \\
\text { (5 studies) }\end{array}$} & \multirow{2}{*}{$\begin{array}{l}\oplus \oplus \oplus \ominus \\
\text { moderate } 1\end{array}$} & \multirow{2}{*}{$\begin{array}{l}\text { Plasma exchange thera- } \\
\text { py increased the chance } \\
\text { of full recovery at } 1 \text { year }\end{array}$} \\
\hline & 546 per 1000 & $\begin{array}{l}\mathbf{6 7 7} \text { per } \mathbf{1 0 0 0} \\
\text { (585 to } 792)\end{array}$ & & & & \\
\hline \multirow{2}{*}{$\begin{array}{l}\text { Relapses at } 1 \text { year } \\
\text { Follow-up: } 6 \text { to } 12 \text { months }\end{array}$} & \multicolumn{2}{|c|}{ Study population } & \multirow{2}{*}{$\begin{array}{l}\text { RR } 2.89 \\
(1.05 \text { to } 7.93)\end{array}$} & \multirow{2}{*}{$\begin{array}{l}649 \\
\text { (6 studies) }\end{array}$} & \multirow{2}{*}{$\begin{array}{l}\oplus \oplus \oplus \ominus \\
\text { moderate }^{1}\end{array}$} & \multirow{2}{*}{$\begin{array}{l}\text { Plasma exchange thera- } \\
\text { py was associated with } \\
\text { a higher risk of relapsing } \\
\text { at } 1 \text { year }\end{array}$} \\
\hline & 12 per 1000 & $\begin{array}{l}\mathbf{3 5} \text { per } 1000 \\
(13 \text { to } 97)\end{array}$ & & & & \\
\hline \multirow{2}{*}{$\begin{array}{l}\text { Deaths at } 1 \text { year } \\
\text { Follow-up: mean } 1 \text { year }\end{array}$} & Study popula & & \multirow{2}{*}{$\begin{array}{l}\text { RR } \mathbf{0 . 8 6} \\
(0.45 \text { to } 1.65)\end{array}$} & \multirow{2}{*}{$\begin{array}{l}649 \\
\text { (6 studies) }\end{array}$} & \multirow{2}{*}{$\begin{array}{l}\oplus \oplus \oplus \oplus \\
\text { high }\end{array}$} & \\
\hline & 55 per 1000 & $\begin{array}{l}\mathbf{4 7} \text { per } 1000 \\
(25 \text { to } 91)\end{array}$ & & & & \\
\hline
\end{tabular}




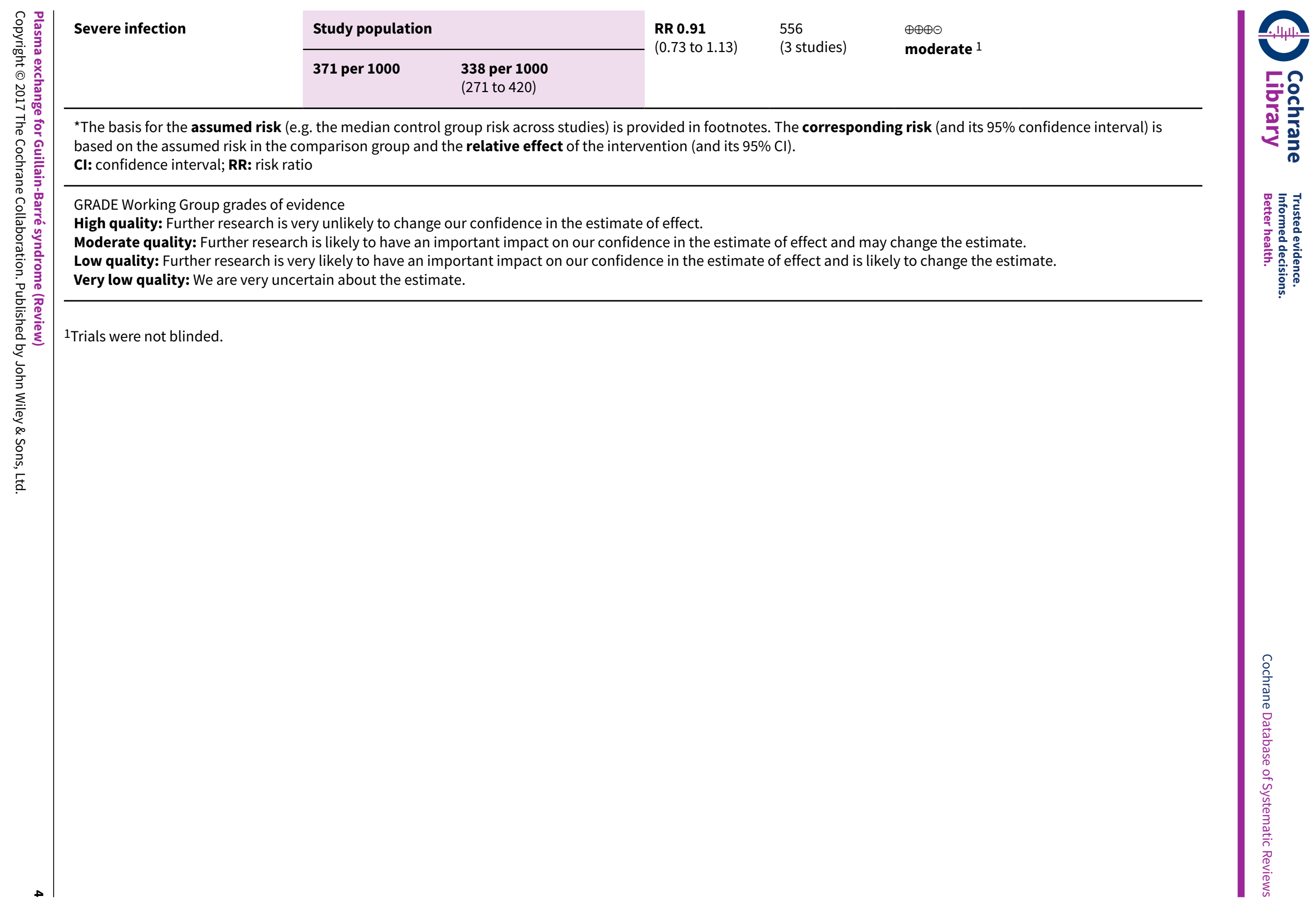




\section{B A C K G R O U N D}

\section{Description of the condition}

Guillain-Barré syndrome (GBS) is an acute, usually symmetrical, and typically ascending, paralysing disorder caused by inflammation of the peripheral nerves. GBS usually occurs as a random and rare event in the general population, at a rate of about 0.5 to 2 cases per 100,000 persons per year. About half the cases follow within a few days to a few weeks of an infection. Some infectious agents implicated as triggering GBS cause gastroenteritis with diarrhoea. Others cause respiratory infections. Many lines of evidence support the likelihood that GBS is an autoimmune disorder, with the person's antibodies targeted to attack various components of peripheral nerve myelin or the axon. In the commonest form of the disease in Europe and North America, acute inflammatory demyelinating polyradiculoneuropathy, the myelin sheath is the target of the immune response but the precise antigen involved remains unknown. In acute motor axonal neuropathy, the commonest form of the disease in parts of Southeast Asia and Central America, the immune response targets the axon at the nodes of Ranvier. In early studies of acute inflammatory demyelinating polyradiculoneuropathy, demyelinating serum factors were identified. Serum of people with GBS was shown to produce electrophysiological and histological signs of acute demyelination in myelinated tissue cultures and following intraneural injection (Cook 1971; Harrison 1984; Sumner 1982). There was a positive correlation between the demyelinating activity and severity of neurological disease (Metral 1989). However, the precise mechanism and target antigen have not yet been identified (Willison 2016). In acute motor axonal neuropathy there is strong evidence that antibodies to gangliosides on the axolemma at the nodes of Ranvier are responsible (Yuki 2012; Willison 2016). Many, but not all, people with GBS recover over months to two or more years. Treatments have been sought to: (1) accelerate recovery, (2) decrease complications during the acute illness, and (3) decrease the amount of long-term residual neurological deficit. Plasma exchange was introduced for the treatment of GBS in the expectation of removing circulating antibodies or other factors responsible for the nerve damage.

\section{Description of the intervention}

Therapeutic plasma exchange has been used in medical conditions for many years, either to remove toxic factors or to replace a missing factor (Shumak 1984). The technique consists of separating plasma from cells using membrane filtration or centrifugation. Cells are re-infused into the person with GBS at the same time as plasma is being removed. Albumin diluted with gelatin or fresh frozen plasma is used to maintain volume and osmotic equilibrium. Plasma exchange has significant constraints and a morbidity associated with it. Specific devices and teams trained in the use of extracorporeal circulation are needed. Clinical efficacy depends on many factors including volume of plasma exchanged, number and frequency of sessions, nature of the replacement solution, and the separating technique.

\section{How the intervention might work}

The first uses of plasma exchange in treatment of GBS were reported between 1978 and 1981, with small uncontrolled series claiming clinical benefit (Brettle 1978; Mark 1980; Ropper 1980; Schooneman 1981; Valbonesi 1981). Since these first reports, six RCTs have been conducted and published comparing plasma exchange with supportive treatment alone (Farkkila 1987; Greenwood 1984; McKhann 1985; Osterman 1984; Raphaël 1987; Raphaël 1997a). Four RCTs showed short-term benefit (McKhann 1985; Osterman 1984; Raphaël 1987; Raphaël 1997a), of which one also showed sustained benefit after 12 months (Raphaël 1992). Another RCT showed the efficacy of plasma exchange in mild forms of the disease (Raphaël 1997a). A narrative review (Raphaël 1996) and one consensus conference (Consensus 1986) recommended the use of plasma exchange in severe GBS (i.e. those who are confined to a chair or to a bed, or mechanically ventilated).

The use of cerebrospinal fluid (CSF) filtration was considered as an alternative to plasma exchange because of the identification of factors that block nerve conduction in the spinal fluid in GBS and other inflammatory disorders (Wollinsky 2001). One such factor is a pentapeptide QYNAD (Gln-Tyr-Asn-Ala-Asp). A single RCT has compared CSF filtration with plasma exchange (Wollinsky 2001).

\section{Why it is important to do this review}

The determination of the size of any beneficial effect of plasma exchange requires a systematic review. The primary aim of the present review was to search systematically for, and combine all evidence from, randomised trials relating to the effects of plasma exchange in GBS in order to supply the best evidence currently available on which to base recommendations for clinical practice and further research. This review intended to take into account known prognostic factors including, age, severity of disability (Raphaël 1997a), presence or absence of sensory deficit, previous history of diarrhoea (PSGBS Group 1997; Visser 1999), reduced distal motor amplitude on electrodiagnostic testing, and time from onset of neuropathy to the start of treatment (McKhann 1985; McKhann 1988). This is an update of a review first published in 2001 and last updated in 2012.

\section{O B JECT IVES}

To assess the effects of plasma exchange for treating GBS.

\section{METHODS}

\section{Criteria for considering studies for this review}

\section{Types of studies}

All randomised or quasi-randomised clinical trials. We made a particular effort to include unpublished randomised studies.

\section{Types of participants}

We included children and adults with GBS of all degrees of severity. GBS was defined according to internationally accepted diagnostic criteria as acute polyradiculoneuropathy causing progressive weakness of two or more limbs, an onset phase of not more than four weeks, reduced or absent tendon reflexes and lacking alternative causes (Asbury 1990). Studies that did not conform exactly to these criteria were included provided that the authors regarded GBS or one of its synonyms, such as acute idiopathic neuropathy or acute inflammatory demyelinating polyradiculoneuropathy, as the preferred diagnosis. 


\section{Types of interventions}

We only considered trials evaluating plasma exchange alone. We considered trials comparing plasma exchange with supportive care or sham exchange, or comparing different modalities of plasma exchange (doses, type of fluid replacement, or separation techniques). We analysed the influence of plasma volume exchanged, number of plasma exchanges, and types of replacement solution.

\section{Types of outcome measures}

\section{Primary outcomes}

The main criterion was time after randomisation to recover walking with aid. In participants who did not lose the ability to walk, we used the time to onset of motor recovery as a main end point, and defined it as the time required to recover at least two functional items or one item with an improvement in cranial nerve function or trunk or respiratory muscle involvement (Raphaël 1992).

\section{Secondary outcomes}

1. We found that the outcome measure 'change in disability grade (Hughes 1978) four weeks after randomisation' was reported as the primary end point in many of the trials included in this metaanalysis, and available in all trials. Thus, this outcome measure was upgraded in the list of secondary end points for this review.

2. Time to recovery of walking without aid.

3. Dependency on a ventilator.

4. Time after randomisation to weaning from the ventilator.

5. Full muscle strength recovery at one year.

6. Deaths at one year.

7. Death or severe sequelae at one year, defined by the loss of at least one of the following six functions: ability to walk, with or without aid, climb stairs, dress, cut meat, or write (Raphaël 1992).

8. Relapses at one year. Relapse is defined by deterioration in strength causing an increase in disability grade (Hughes 1978), or loss of two or more items of the functional muscle strength scale (Raphaël 1997a), for at least one week.

9. Complications:

a. development of new infection treated with antibiotics;

b. development of hypertension requiring drug treatment;

c. other autonomic disorders: unexplained drop in systolic blood pressure by more than $20 \mathrm{~mm} \mathrm{Hg}$, unexplained drop in heart rate by more than 20 beats per minute, or unexplained rise in heart rate above 120 beats per minute.

10.Discontinuation of plasma exchange (owing to poor haemodynamic tolerance).

\section{Search methods for identification of studies}

\section{Electronic searches}

We searched the following databases without language restriction:

- Cochrane Neuromuscular Specialised Register (searched 18 January 2016);

- Cochrane Central Register of Controlled Trials (CENTRAL; searched 18 January 2016 in the Cochrane Central Register of Studies Online);

- MEDLINE (January 1966 to 18 January 2016); and
- Embase (January 1980 to 18 January 2016).

We also searched the following trials registries in January 2016:

- US National Institutes of Health Ongoing Trials Register ClinicalTrials.gov (clinicaltrials.gov); and

- World Health Organization (WHO) International Clinical Trials Registry Platform (ICTRP; http://www.who.int/ictrp/en/).

The search strategies are in the appendices: Cochrane Neuromuscular Specialised Register (Appendix 1), CENTRAL (Appendix 2), MEDLINE (Appendix 3), Embase (Appendix 4), ClinicalTrials.gov (Appendix 5), and WHO ICTRP (Appendix 6).

\section{Searching other resources}

We checked the bibliographies in reports of the randomised trials and contacted their authors to identify additional published or unpublished data. We also searched the NHS Economic Evaluation Database and contacted other experts in the field seeking information about additional trials.

\section{Data collection and analysis}

\section{Selection of studies}

Two review authors (DA and RACH) checked titles and abstracts identified from the searches. Both of these review authors obtained the full texts of all potentially relevant studies and assessed them independently. They decided which trials fitted the inclusion criteria and resolved any disagreements about inclusion criteria by discussion.

\section{Data extraction and management}

A single review author (DA) performed data extraction and a second review author (SC) checked the data extraction. We obtained missing data from the trial authors whenever possible.

\section{Assessment of risk of bias in included studies}

Two review authors (DA and RACH) independently assessed the risk of bias in included studies. The assessment of risk of bias followed the methods recommended in the Cochrane Handbook for Systematic Reviews of Interventions and took into account random sequence allocation, allocation concealment, participant blinding, observer blinding, incomplete outcome data (completeness of follow-up), selective reporting, and other sources of bias, such as explicit diagnostic criteria, explicit outcome criteria, and how studies dealt with baseline differences between the experimental groups (Higgins 2011). We graded the risk as unclear if we were unable to obtain the relevant information. If judgements were inconsistent, we reassessed the studies and reached agreement by consensus.

\section{Measures of treatment effect}

We expressed results as risk ratios (RRs) with 95\% confidence intervals (Cls) for dichotomous outcomes and mean differences (MD) with $95 \% \mathrm{Cls}$ for continuous outcomes. We tried to analyse all the primary and secondary outcomes included in our protocol.

\section{Unit of analysis issues}

For this review, all the trials identified were parallel-group RCTs that did not raise unit of analysis issues. 


\section{Dealing with missing data}

For this review, we did not replace missing data.

\section{Assessment of heterogeneity}

We tested for heterogeneity using the $\mathrm{I}^{2}$ statistic (Higgins 2011). We intended to perform a sensitivity analysis with a random-effects model for any unexplained heterogeneity. We found that only one of the many tests of heterogeneity was significant (for Analysis 1.4), so we considered a fixed-effect model appropriate.

\section{Assessment of reporting biases}

If we had been able to pool more than 10 trials, we would have created and examined a funnel plot to explore possible small study biases.

\section{Data synthesis}

We calculated a weighted treatment effect (using a fixed-effect model) across trials using the Cochrane statistical package Review Manager 5.3 (RevMan 2014).

\section{'Summary of findings' table}

We created a 'Summary of findings' table with the following outcomes:

1. walking with aid at four weeks;

2. dependency on a ventilator at four weeks;

3. full muscle strength recovery at one year;

4. relapses at one year;

5. deaths at one year;

6 . severe infection.

In the 'Summary of findings' table, we presented an alternative formulation of our primary outcome: 'walking with aid after four weeks' rather than 'time to recover walking with aid'.

We used the five GRADE considerations (study limitations, consistency of effect, imprecision, indirectness, and publication bias) to assess the quality of the body of evidence (studies that contributed data for the prespecified outcomes). For these, we used methods and recommendations described in the Cochrane Handbook for Systematic Reviews of Interventions (Higgins 2011), using GRADEpro software (GRADEpro 2008). We justified all decisions to downgrade or upgrade the quality of studies using footnotes and made comments to aid readers' understanding of the review where necessary.

\section{Subgroup analysis and investigation of heterogeneity}

We attempted to analyse subgroups of interest that had been predefined and chosen because of their prognostic importance in prospective studies and trials. The subgroups were defined according to the status of the participants at randomisation as follows:

1. younger and older (children under 10 years, children over 10 years; and adults up to 49 years of age; adults aged 50 years or more);
2. more severely or less severely affected (walking, not walking or requiring ventilation);

3. having or not having documented relevant sensory deficit on routine neurological examination (symptoms alone were ignored);

4. having or not having a history of diarrhoea (gastroenteritis) within the six weeks before the onset of neuropathic symptoms;

5. time from onset of neuropathy to start of treatment (7 days or less after onset, more than 7 up to 14 days after onset, and more than 14 days after onset);

6. number of plasma exchanges (one, two, and three or more);

7. separation technique: filtration or centrifugation (i.e. continuous or discontinuous);

8. type of replacement fluids, albumin plus gelatin or fresh frozen plasma.

\section{Sensitivity analysis}

We would have carried out a sensitivity analysis based on study quality (risk of bias) if we had needed to explore heterogeneity. For any unexplained heterogeneity, we would have carried out a sensitivity analysis using a random-effects model.

\section{RES U LTS}

\section{Description of studies}

\section{Results of the search}

The numbers of new papers found by the updated searches in January 2016 were Cochrane Neuromuscular Specialised Register 14, CENTRAL 27, MEDLINE 56, Embase 46, and NHS Economic Evaluation Database 5. There were 112 papers after deduplication. We identified three additional records from the trials registry searches.

The search strategy identified 38 potentially relevant articles. Twenty of these articles were excluded on the basis of the contents of their title and abstract. Two papers were reviews on the general use of plasma exchange, and two others were related to chronic inflammatory demyelinating polyradiculoneuropathy. Eleven papers reported studies that evaluated steroids (one study) or intravenous immunoglobulins (IVIgs) (10 studies); we did not include these as other Cochrane systematic reviews have evaluated these therapies. Two papers were commentaries about treatments for GBS. Three additional papers were related to prognostic factors in GBS. Among the remaining 18 papers, the study by Mendell (Mendell 1985; Mendell 1985b) and the North American study (McKhann 1985; McKhann 1985b) were each published in two different papers. Five articles reported complementary information from one single trial (Bouget 1993; Raphaël 1985; Raphaël 1986; Raphaël 1987; Raphaël 1992) and two other articles reported complementary results from another single trial (Farkkila 1987; Farkkila 1992). Another paper reported the results of three different trials (Raphaël 1997a). Hence we identified 14 potentially relevant trials that have evaluated plasma exchange for GBS, eight of which fulfilled predefined selection criteria for inclusion in the review.

See Figure 1 for a flow chart of the study selection process. 
Figure 1. Study flow diagram.

8 studies included in previous
version of the review

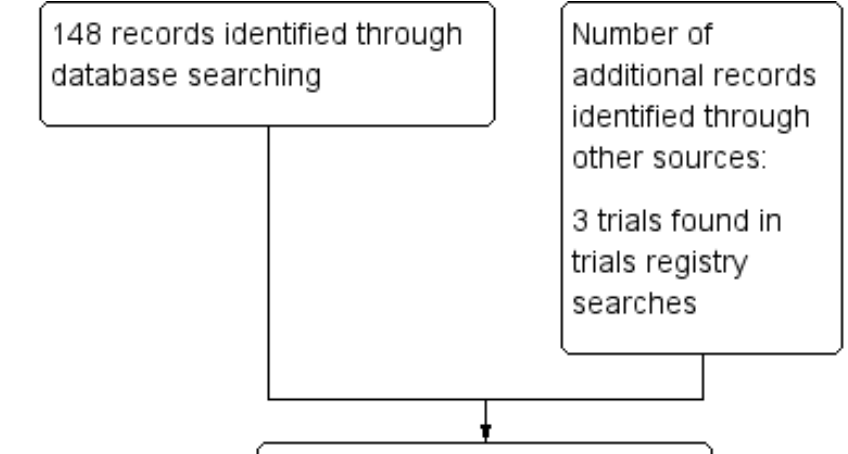

112 records after duplicates removed
74 records

excluded

20 full-text articles excluded, with reas

Some papers exclu for more than one reason

2 were reviews

2 were commentari

2 concerned chron inflammatory demyelinating polyradiculoneurop not GBS

11 concerned corticosteroids 10 concerned IVIg 38 full-text articles assessed for 3 concerned eligibility

prognostic factors 
Figure 1. (Continued)

6 studies included
in quantitative
synthesis
(meta-analysis)

\section{Included studies}

All the eight included trials had explicit diagnostic criteria similar to those of Asbury 1990. See Characteristics of included studies.

Six of the eight trials compared plasma exchange alone to supportive care.

In Greenwood 1984, 29 participants with GBS within two weeks from onset of motor deficit who were unable to walk without assistance were randomised to receive either five sessions of plasma exchange in five days or only supportive care. At each session, $55 \mathrm{~mL} / \mathrm{kg}$ of plasma were exchanged and substitution consisted of purified proteins and crystalloid. The primary end point was improvement in disability grade one month after completion of treatment. Participants in both arms were comparable for baseline characteristics, notably for the proportion of participants on ventilator (12/15 versus $8 / 14)$, and participants were followed up for one year. Seven of the 14 participants in the treated group improved by one or more grades at one month, compared to $6 / 15$ in the control group. Similarly, after one year, there was no difference between the two arms for the number of deaths (2/14 versus $2 / 15)$, for the number of participants who recovered fully (4/14 versus $4 / 15)$, or for the number of relapses $(1 / 14$ versus $1 / 15)$. Two participants in the treated group had episodes of haemorrhage and two additional participants in the treated group had venous thrombosis, while no such complications were seen in the control group.

In Osterman 1984, 38 adults with GBS within two weeks from onset of motor deficit who were unable to walk without assistance were randomised to receive either plasma exchange $(\mathrm{N}=18)$ or supportive care $(\mathrm{N}=20)$. In the treatment group, the intermittent flow technique was used in five to eight sessions over seven to 10 days in eight participants. In 10 participants, three or four sessions over three to seven days were done using the continuous flow technique. In each session, a total of $3 \mathrm{~L}$ of plasma was removed. The main outcome measure was improvement of muscle strength based on a muscular weakness score and functional disability grade. Analyses were done on an intention-to-treat basis. The two groups were comparable for baseline characteristics, notably for the proportion of participants being on ventilator ( $2 / 20$ versus $0 / 18$ ) and follow-up. Six of 20 participants in the control group compared to $14 / 18$ in the treated group improved by one or more disability grades at one month $(P<0.025)$. After one year, $17 / 18(95 \%)$ participants in the treated group had complete muscle strength recovery (disability grade 0 or 1 ) compared to $16 / 20(80 \%)$ in the control group. No serious adverse events were reported.

In McKhann 1985, 245 children and adults with GBS within 30 days from onset of motor deficit who were unable to walk without assistance were randomised to receive either supportive care alone or three to five plasma exchanges in seven to 14 days. At each session, $40 \mathrm{~mL} / \mathrm{kg}$ of plasma was removed. Substitution consisted of a $5 \%$ solution of processed human plasma protein in normal saline in most participants, except for 12 who received fresh frozen plasma. The main outcome measure was proportion of participants who improved at least one grade at one month. Analyses were done on an intention-to-treat basis. Subgroup analyses were defined a priori for participants needing or not needing respiratory assistance and for plasmapheresis technique (centrifugation versus filtration). The two groups were closely similar for baseline characteristics, notably for the proportion of participants being on ventilator (52/123 versus 57/122) and follow-up. Thirty-nine per cent of participants in the control group compared to $59 \%$ in the treated group improved by one or more grades at one month $(P<0.01)$. For participants needing respiratory assistance at inclusion, $35 \%$ in the control group compared to $50 \%$ in the treated group improved by one or more disability grades at one month $(P<0.01)$. The median time to recover walking unaided was shortened in the treatment group by 32 days for all participants $(P<0.001)$, and by 72 days for participants initially on a ventilator $(P<0.01)$. After six months, $18 \%$ in the treated group failed to recover walking unaided compared to $29 \%$ in the control group $(P<0.05)$. The authors found no significant difference in the nature or frequency of serious adverse events in the two arms. The authors provided the comparison between the two techniques for plasma exchange in another paper that is detailed below (McKhann 1988).

In Farkkila 1987, 29 adults with GBS within two weeks from onset of motor deficit were randomised to receive either three to five sessions of plasma exchange or only supportive care. In each session, a total of $3 \mathrm{~L}$ of plasma was removed. The main outcome measure was hand grip force evaluated every day for the first week then every second day the second week after treatment initiation. One participant in the treated group was considered to have a form of relapsing polyradiculoneuritis and two other participants (one in each group) had poliomyelitis and were excluded. The groups of participants were comparable for baseline characteristics, notably for the proportion of participants being on ventilator $(3 / 13$ versus 4/13) and follow-up. Isometric muscle force increased faster in the treated group and was significantly greater than in the control group throughout the three-week follow-up period $(P<0.001)$. The mean ( \pm standard deviation (SD)) time on ventilator was slightly shortened in the treated group $(\mathrm{N}=4)$ compared to the control group $(\mathrm{N}=3)(11.7 \pm 12.2$ days versus $15.3 \pm 6.1$ days, $\mathrm{P}=0.50)$. The authors did not provide the time to recover walking with aid or the proportion of participants with one or more disability grades improvement at one month. The authors stated that the two groups were comparable after one year, but did not provide any data. The mean time to hospital discharge was slightly reduced in the treated group compared to the control group ( $48.4 \pm 34.5$ days versus 53.0 \pm 38.9 days, $P=0.26$ ). The mean recovery time was almost identical between the two groups $(76.6 \pm 88.4$ days versus $79.1 \pm 55.8$ days, $P=$ 
0.75). Mild temporary falls in blood pressure were the only reported side effects related to plasma exchange.

In the Raphaël 1987, 220 adults with GBS within two weeks from onset of motor deficit were randomised to receive either four sessions of plasma exchange in eight days or supportive care. In the treated group, participants were randomised to receive plasma exchange with total volume replacement with fresh frozen plasma or replacement with diluted albumin and gelatine solution, each $50 \%$ of the total volume replacement. In each session, a total of $3 \mathrm{~L}$ of plasma was removed. The main outcome measure was the time to recover walking with assistance (disability grade 3 ). Intentionto-treat analyses were performed. Comparison of the Kaplan-Meier curves indicating the proportion of participants who recovered walking with assistance during the 180 days of follow-up showed significantly faster improvement in the plasma exchange group (median, 44 days versus 30 days, one-tailed Breslow test $P<0.01$ ). The number of participants with one or more grade improvement at one month was $67 / 109$ in the treated group compared to $41 / 111$ in the control group $(P<0.001)$. Separate analyses were done for participants needing mechanical ventilation at randomisation (43/111 versus 39/109). In this subset of participants, the median time to onset of recovering walking with assistance was shorter in the plasma exchange arm compared to the control arm (76 days versus 50 days, $P<0.05)$. The authors did not find any significant differences between the two types of volume replacement in the plasma exchange group, regardless of the outcome measures. The trial authors found a lower rate of blood pressure instability or bradycardia in the treated group compared to the control group (36\% versus $26 \%, P<0.05$ and $43 \%$ versus $25 \%, P<0.005$, respectively). There were also fewer episodes of lung infection ( $46 \%$ versus $33 \%, P<0.05)$ and a higher proportion of septicaemia $(5 \%$ versus $13 \%, P<0.05)$ in the plasma exchange arm compared to the control arm. After one year, 14 participants had died, seven in each group (Raphaël 1992). Nine participants were lost to follow-up, six in the control group and three in the treatment group. The authors found that, at one year, a greater proportion of participants had recovered full muscle strength in the treatment group than in the control group ( $71 \%$ versus $52 \%, P=0.007$ ).

In Raphaël 1997a, 91 adults with GBS who were able to stand up alone or to walk with assistance (disability grade 1 to 3 ) were randomised to receive either two sessions of plasma exchange in three days or supportive care. For plasma exchange, fluid replacement consisted of diluted albumin and gelatine solution, each accounting for half of the total volume replaced. In each session, a total of $3 \mathrm{~L}$ of plasma was removed. The main outcome measure was the time to onset of motor recovery, defined by improvement of at least two items of a functional muscular score or one item and improvement in cranial nerve function or trunk or respiratory involvement. Intention-to-treat analyses were done. The two arms were comparable for baseline characteristics and follow-up. In the treated group, the median time to onset of motor recovery was significantly shortened compared to the control group ( 8 days versus 4 days, $P=0.0002$ ). The number of participants with one or more grades of improvement at one month was significantly higher, 26/45 in the treated group compared to 13/46 in the control group $(P<0.001)$. Two participants discontinued plasma exchange due to adverse events.

Two trials compared two different numbers of sessions of plasma exchange in adults with GBS. As these trials did not have a control group with only supportive care, we did not include them in the meta-analysis of plasma exchange versus supportive care. In Raphaël 1997b, 304 adults with GBS who were unable to stand unaided were randomised to receive either four sessions of plasma exchange in nine days $(N=155)$ or two sessions of plasma exchange in three days $(\mathrm{N}=149)$. For plasma exchange, fluid replacement consisted of diluted albumin and gelatine solution, each accounting for half of the total volume replaced. In each session, a total of $3 \mathrm{~L}$ of plasma was removed. The main outcome measure was the time to recover walking with assistance (disability grade 3). Intention-to-treat analyses were done. The two arms had comparable baseline characteristics and follow-up. In the four sessions of plasma exchange group, the median time to recover walking with assistance was significantly shortened compared to the two sessions of plasma exchange group (24 days versus 20 days, $P=0.04)$. Similarly, the median time on a ventilator and the median time to hospital discharge were significantly shortened in the four sessions of plasma exchange group ( 37 days versus 25 days, $P=0.005$, and 26 days versus 21 days, $P=0.04$, respectively). At one year, a higher proportion of participants in the four sessions of plasma exchange group had recovered full muscle strength compared to the two sessions of plasma exchange group (64\% versus $48 \%, P=0.006$ ). The trial authors found a slightly higher rate of systolic blood pressure instability related to plasma exchange and a higher rate of haematomas at the venous puncture site in the four sessions of plasma exchange arm compared to the two sessions of plasma exchange arm ( $18 \%$ versus $29 \%, \mathrm{P}=0.04$ and $6 \%$ versus $15 \%, P=0.02$, respectively). At one year, there were 11 deaths $(7 \%)$ in the four sessions of plasma exchange arm $(N=155)$ and 3 deaths $(2 \%)$ in the two sessions of plasma exchange arm (N $=149)(P=0.052)$.

In the second trial comparing different numbers of plasma exchanges (Raphaël 1997c), 161 adults with GBS who needed mechanical ventilation were randomised to receive either six sessions of plasma exchange in 13 days $(\mathrm{N}=80)$ or four sessions of plasma exchange in nine days $(\mathrm{N}=81)$. For plasma exchange, fluid replacement consisted of diluted albumin and gelatine solution, each accounting for half of total volume replacement. In each session, a total of $3 \mathrm{~L}$ of plasma was removed. The main outcome measure was the time to recover walking with assistance (disability grade 3). Intention-to-treat analyses were done. The two arms had comparable baseline characteristics and follow-up. The authors did not find any statistically significant difference between the two arms regardless of the outcome measures except for serious adverse events. There was a higher rate of systolic blood pressure instability related to plasma exchange in the six-session plasma exchange group compared to the four-session plasma exchange group $(26 \%$ versus $46 \%, P=0.001)$. At one year, there were four deaths $(5 \%)$ in the six-session plasma exchange group $(\mathrm{N}=80)$ and two deaths (2\%) in the four-session plasma exchange group ( $N=81)$ $(P=0.44)$.

\section{Excluded studies}

We excluded six potentially eligible trials (see Characteristics of excluded studies). One trial had no control group (de-Zoysa 1994). The second trial compared two different strategies of fluid replacement for plasma exchange in 12 participants with either myasthenia gravis or GBS, and we were unable to obtain separate data for GBS (Rock 1997). In the third trial, plasma exchange was compared to plasma perfusion (Morosetti 1994). Another trial randomised 25 adults with GBS to receive either nine sessions 
of plasma exchange in 20 days plus prednisone $100 \mathrm{mg}$ orally for 10 days, then $100 \mathrm{mg}$ on alternate days for 20 days and gradually discontinued over the next 21 days, or supportive care alone (Mendell 1985b). The main outcome measure was muscle strength assessed by a 10-point scale, evaluated repeatedly for 24 weeks. Analyses were done on an intention-to-treat basis. The two groups were comparable for baseline characteristics, except for sex ratio (more females in the treated group) and follow-up. The trial authors did not observe any significant difference between the two groups, regardless of the outcome measure. This trial was not included because the intervention involved both plasma exchange and corticosteroids, so the effect of plasma exchange alone could not be determined. One trial compared plasma exchange (five or six sessions for a total of 8 to $12 \mathrm{~L}$ of volume replacement) to CSF filtration in 37 adults with GBS (Wollinsky 2001). CSF filtration consisted of five or six cycles of $30 \mathrm{~mL}$ to $50 \mathrm{~mL}$ of CSF filtered and reinstilled daily for 15 consecutive days. The main outcome measure was the improvement in disability grade at four weeks. Analyses were done on an intention-to-treat basis. Twenty participants were assigned to plasma exchange and 17 to CSF filtration. At baseline, there were slightly more participants on mechanical ventilation in the CSF filtration group (5/17) than in the plasma exchange group (2/18), and the median time from onset of disease and randomisation was slightly shorter in the CSF filtration group (3 days, range 1 to 30 days) than in the plasma exchange group (6.5 days, range 1 to 29 days). The median improvement within four weeks was similar in both groups: 0 grades in the CSF filtration group and 0.5 grades in the plasma exchange group. There was no significant difference between the two treatment arms for any of the secondary outcomes. As plasma exchange was compared to CSF filtration, we did not include the trial in the review, but it has been included in another (Hughes 2011). The sixth excluded trial (El Bayoumi 2011) compared plasma exchange to IVIg in children with GBS requiring mechanical ventilation. This trial has been included in the review of IVIg (Hughes 2014).

\section{Risk of bias in included studies}

See Figure 2 and the 'Risk of bias' tables in Characteristics of included studies. 
Figure 2. Risk of bias summary: review authors' judgements about each risk of bias item for each included study. Green $(+)=$ low risk of bias, yellow $(?)=$ unclear risk of bias, red $(-)=$ high risk of bias.

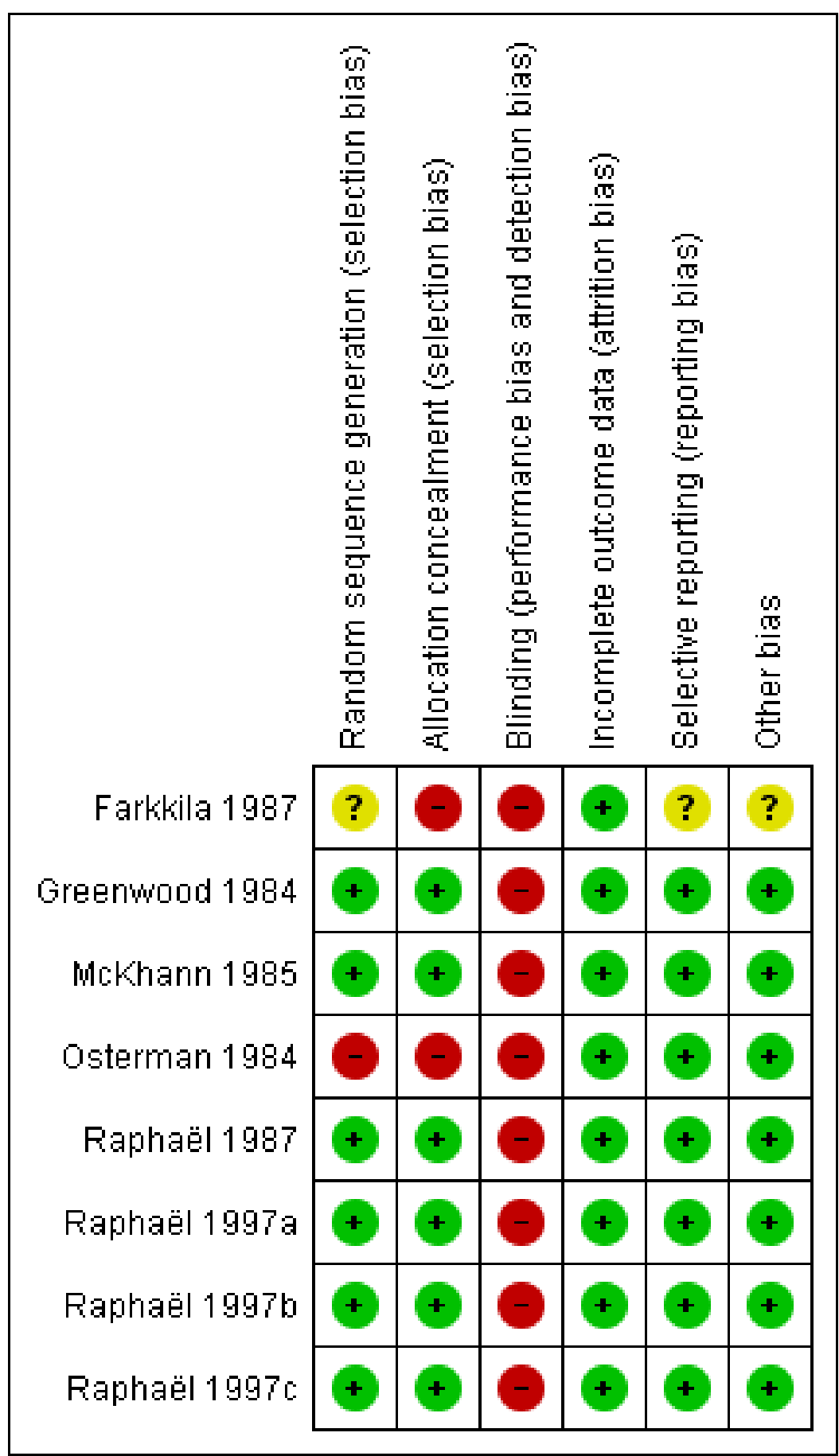

Overall, the eight studies had good methodological quality. Only two studies had inadequate allocation concealment, as they used alternate allocation (Farkkila 1987; Osterman 1984). We graded all trials at high risk of bias for participant blinding. Sham apheresis would have been the only method for participant blinding, and it was thought unethical by all authors. Only two trials made an effort to keep the observer unaware of the treatment to which the participant was assigned (McKhann 1985; Osterman 1984). Four trials attempted to minimise potential bias related to unblinded outcome assessment by centralised review of case reports (McKhann 1985; Osterman 1984; Raphaël 1987; Raphaël 1997a).

\section{Effects of interventions}

See: Summary of findings for the main comparison Plasma exchange compared to sham exchange or supportive treatment for Guillain-Barré syndrome 
We created a 'Summary of findings' tables for treatment effects and treatment complications of plasma exchange versus sham exchange or supportive treatment for GBS (Summary of findings for the main comparison).

\section{Primary outcome}

\section{Time after randomisation to recover walking with aid}

Only two trials (311 participants) reported this outcome measure (Raphaël 1987; Raphaël 1997a). In the first study ( $N=220)$, the median time to recover walking with aid was significantly shortened in the plasma exchange group compared to the control group ( 30 days versus 44 days, $\mathrm{P}<0.01$ ). In the second study $(\mathrm{N}=$ 91), which involved people with mild forms of GBS (see Raphaël 1997a in Included studies for definition), the median time to recover walking aided was not different (12 days in the plasma exchange group compared to 14 days in the control group $(P=0.80)$ ).

This outcome was also assessed as the proportion of participants who recovered walking with assistance after four weeks.

We pooled the data from three trials $(\mathrm{N}=349)$ (Osterman 1984; Raphaël 1987; Raphaël 1997a). After four weeks, 73/172 participants in the treated group had recovered walking with aid, significantly more than the $47 / 177$ in the control group (RR 1.60, $95 \% \mathrm{Cl} 1.19$ to 2.15 , Analysis 1.1 ). We considered that there was no important heterogeneity across the trials $\left(\mathrm{I}^{2}=34 \% ; \mathrm{Chi}^{2}=3.04, \mathrm{P}=\right.$ 0.22).

\section{Time to onset of motor recovery (for mild GBS, i.e. people able to walk with assistance at inclusion)}

One trial provided data on time to onset of motor recovery (Raphaël 1987). In this study, the median time of onset of motor recovery was shortened in the plasma exchange group $(\mathrm{N}=109)$ compared to the control group $(N=111)$, to six days versus 10 days $(P<0.0001)$.

\section{Secondary outcomes}

\section{Change in disability grade (Hughes 1978) four weeks after randomisation}

This outcome measure was analysed in two ways at four weeks, first as the number of participants with one or more disability grade change and second as the mean grade change (Summary of findings for the main comparison).

Five trials provided the number of participants with one or more disability grade change at one month $(\mathrm{N}=623)$. Of these participants, 176/308 in the treated group had improved by one or more grades compared to $110 / 315$ in the control group, RR 1.64 $(95 \% \mathrm{Cl} 1.37$ to 1.96$)$ in favour of the plasma exchange group (Figure 3; Analysis 1.2).

Figure 3. Forest plot of comparison: 1 Plasma exchange compared to sham exchange or supportive treatment for Guillain-Barré syndrome, outcome: 1.2 Improved or not by 1 grade after 4 weeks.

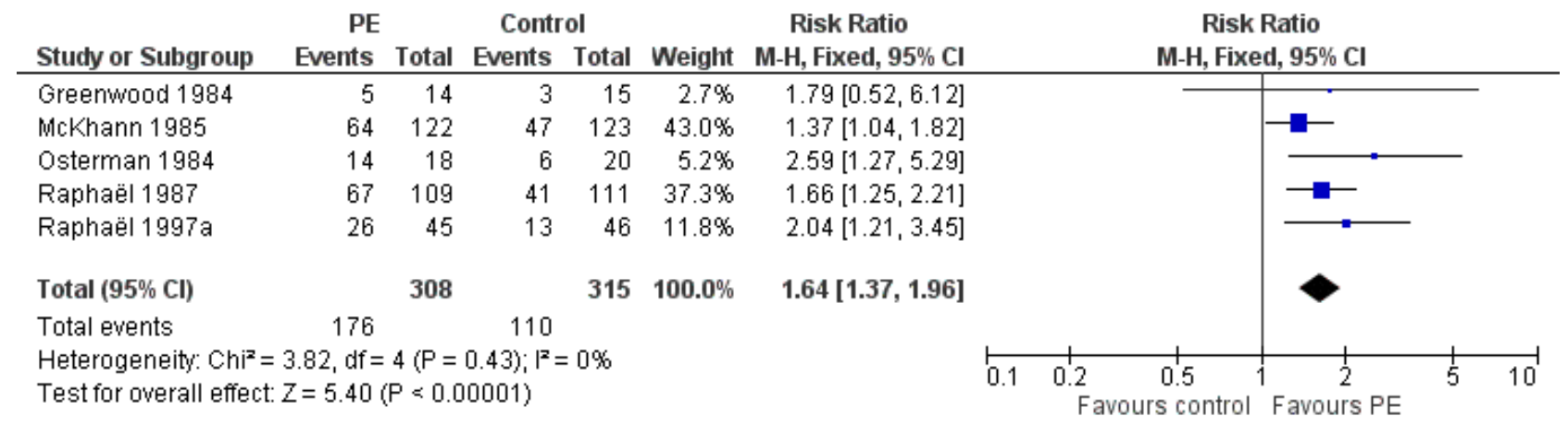

All five trials reported the mean grade change at four weeks. However, Osterman $1984(\mathrm{~N}=38$ ) used a different disability scale from all other trials and so we omitted the trial from this analysis. In McKhann 1985 ( $\mathrm{N}=245)$, the SD of the mean was not available and so we were unable to estimate the MD. The mean grade change was 1.1 grade in the treated group compared to 0.4 grade in the control group $(P<0.001)$. When pooling the data of the three other trials $(\mathrm{N}=340)$, the MD was $-0.97(95 \% \mathrm{Cl}-1.28$ to -0.67$)$ grade change in favour of plasma exchange. We also analysed the results by giving empirical values, the largest in the table, to the SDs for McKhann 1985. The results were qualitatively similar to those obtained without including McKhann 1985 and they were only slightly quantitatively altered. The MD was $-0.89(95 \% \mathrm{Cl}-1.14$ to -0.63 , Analysis 1.3$)(\mathrm{N}=585)$.

\section{Time to recovery of walking without aid}

Two trials $(\mathrm{N}=465)$ reported this outcome measure (McKhann 1985; Raphaël 1987). The median time to recover walking unaided was significantly shortened in the plasma exchange group compared to the control group in McKhann $1985(\mathrm{~N}=245)$ (53 days versus 85 days, $\mathrm{P}<0.001)$ and in Raphaël $1987(\mathrm{~N}=220)$ (70 days versus 111 days, $\mathrm{P}<0.001)$

We also assessed this outcome as the proportion of participants who recovered walking unaided after four weeks. We were able to pool the data from three trials (349 participants) (Osterman 1984; Raphaël 1987; Raphaël 1997a). There were 35/172 participants in the treated group compared to $21 / 177$ participants in the control group who had recovered walking without aid after four weeks (RR $1.72,95 \% \mathrm{Cl} 1.06$ to 2.79 ) in favour of plasma exchange (Analysis 1.4). There was significant heterogeneity in the results $\left(I^{2}=75 \%\right.$; $\mathrm{Chi}^{2}=7.94, \mathrm{P}=0.02$ ) that could be explained by difference in the severity of illness in one study (Raphaël 1997a), compared to the two others (Osterman 1984; Raphaël 1987). Indeed Raphaël 1997 a included only participants with mild GBS, who could walk or stand unaided at inclusion. In this study, there was no significant difference between the plasma exchange group and the control 
group for the proportion of participants who had recovered walking unaided after four weeks. Excluding the data from Raphaël 1997a removed the heterogeneity and the RR for improvement increased to 3.81 (95\% $\mathrm{Cl} 1.61$ to 9.06$)$. However, we reported the pooled data of all studies to reflect a 'real' treatment effect.

\section{Dependency on a ventilator}

In all trials, the proportion of participants being ventilated at inclusion was not statistically different between the plasma exchange group and the control group. The proportion of participants on the ventilator at four weeks after randomisation was available in five studies for a total of 623 participants. At one month, 44/308 participants in the treated group needed mechanical ventilation compared to $85 / 315$ participants in the control group. The RR of being mechanically ventilated was 0.53 $(95 \% \mathrm{Cl} 0.39$ to 0.74$)$, significantly in favour of the plasma exchange group (see Analysis 1.5 and Figure 4).

Figure 4. Forest plot of comparison: 1 Plasma exchange compared to sham exchange or supportive treatment for Guillain-Barré syndrome, outcome: 1.5 On or not on a ventilator after 4 weeks.

\begin{tabular}{|c|c|c|c|c|c|c|c|c|c|c|}
\hline Study or Subgroup & $\begin{array}{r}\text { PE } \\
\text { Events }\end{array}$ & Total & $\begin{array}{l}\text { Contr } \\
\text { Events }\end{array}$ & $\begin{array}{l}\text { ol } \\
\text { Total }\end{array}$ & Weight & $\begin{array}{c}\text { Risk Ratio } \\
\text { M-H, Fixed, 95\% Cl }\end{array}$ & \multicolumn{4}{|c|}{$\begin{array}{c}\text { Risk Ratio } \\
\text { M-H, Fixed, 95\% Cl }\end{array}$} \\
\hline Greenwood 1984 & 2 & 14 & 5 & 15 & $5.7 \%$ & $0.43[0.10,1.86]$ & & & 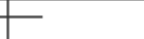 & \\
\hline McKhann 1985 & 26 & 122 & 34 & 123 & $40.1 \%$ & $0.77[0.49,1.20]$ & & & $\mid$ & \\
\hline Osterman 1984 & 4 & 18 & 5 & 20 & $5.6 \%$ & $0.89[0.28,2.81]$ & & & & \\
\hline Raphaël 1987 & 12 & 109 & 38 & 111 & $44.5 \%$ & $0.32[0.18,0.58]$ & & & & \\
\hline Raphaël 1997a & 0 & 45 & 3 & 46 & $4.1 \%$ & $0.15[0.01,2.75]$ & & & & \\
\hline Total $(95 \% \mathrm{Cl})$ & & 308 & & 315 & $100.0 \%$ & $0.53[0.39,0.74]$ & & & & \\
\hline Total events & 44 & & 85 & & & & & & & \\
\hline $\begin{array}{l}\text { Heterogeneity: } \mathrm{Chi}^{2}= \\
\text { Test for overall effect }\end{array}$ & $\begin{array}{l}7.03, \mathrm{df}= \\
Z=3.82\end{array}$ & $\begin{array}{l}4(P= \\
P=0.0\end{array}$ & $\begin{array}{l}0.13) ;\left.\right|^{2}= \\
0001)\end{array}$ & $43 \%$ & & & 0.005 & $\begin{array}{l}0.1 \\
\text { Favours PE }\end{array}$ & 1 Favours & 200 \\
\hline
\end{tabular}

\section{Time after randomisation to weaning from the ventilator}

This outcome was analysed as the mean duration of mechanical ventilation for participants being ventilated at inclusion. This outcome measure could be retrieved from two studies $(N=249)$. In the first study $(\mathrm{N}=29)$ the mean (SD) duration on the ventilator was $11.7(12.2)$ days in the treated group $(\mathrm{N}=4)$ versus $15.3(6.1)$ days in the control group ( $N=3$ ) (Farkkila 1987). In the second study ( $N=220)$, the mean (SD) duration of ventilation was 27.5 (29.3) days in the treated group compared to 33.3 (23.2) days in the control group (Raphaël 1987). When we pooled the data of these two studies, the mean time on a ventilator was slightly but not significantly shortened in the treatment group, with a MD of -5.09 days $(95 \% \mathrm{Cl}-12.94$ to $2.76, \mathrm{P}=0.20)$. In another trial $(\mathrm{N}=245)$, in participants being ventilated before randomisation, the median time on ventilator was slightly reduced in the treatment group ( 27 days versus 33 days) (McKhann 1985). This study did not provide the mean and SD values, and we did not include it in the pooled data.

\section{Full muscle strength recovery at one year}

Information for full muscle strength recovery at one year could be obtained from five trials for a total of 404 participants (Farkkila 1987; Greenwood 1984; Osterman 1984; Raphaël 1987; Raphaël 1997a). Of these participants, $135 / 199$ in the treated group had recovered full muscle strength after one year compared to $112 / 205$ in the control group. Thus, the RR of having recovered full muscle strength after one year was $1.24(95 \% \mathrm{Cl} 1.07$ to 1.45 , see Analysis 2.1, Figure 5 and Summary of findings for the main comparison) significantly in favour of treatment with plasma exchange.

Figure 5. Forest plot of comparison: 2 Plasma exchange compared to sham exchange or supportive treatment for Guillain-Barré syndrome, outcome: 2.1 Full muscle strength recovered or not at 1 year.

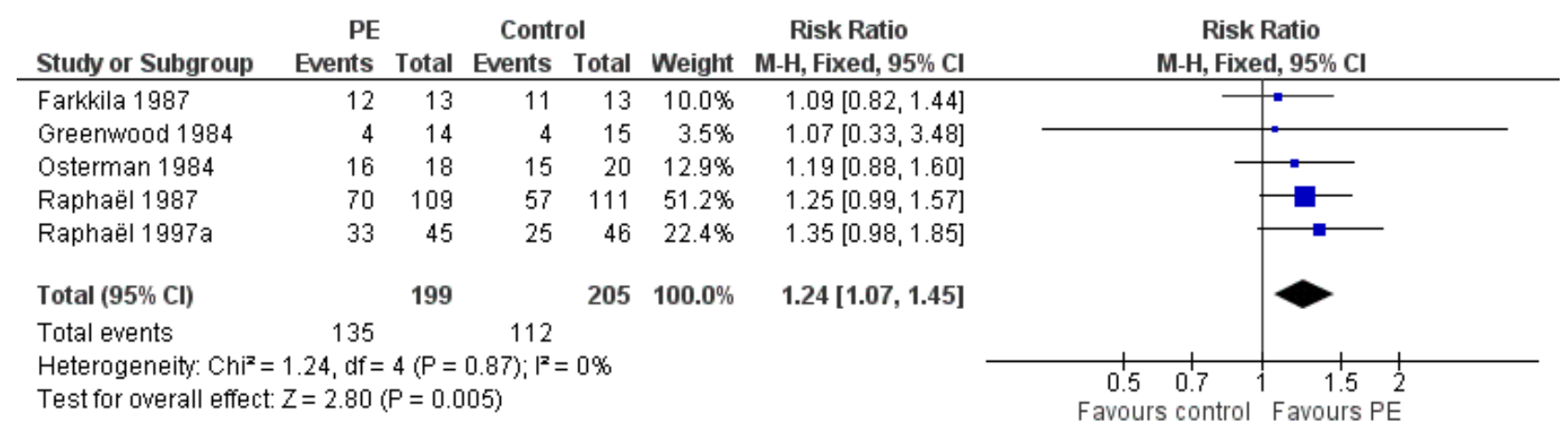




\section{Deaths at one year}

This outcome measure could be obtained from six trials for a total of 649 participants (Farkkila 1987; Greenwood 1984; McKhann 1985; Osterman 1984; Raphaël 1987; Raphaël 1997a). There were 15/321 deaths after one year in the treated group, compared to $18 / 328$ in the control group (RR $0.86,95 \% \mathrm{Cl} 0.45$ to 1.65; see Analysis 2.2 and Summary of findings for the main comparison).

\section{Severe sequelae at one year}

This outcome measure could be obtained from six trials ( $\mathrm{N}=$ 649) (Farkkila 1987; Greenwood 1984; McKhann 1985; Osterman 1984; Raphaël 1987; Raphaël 1997a). In the treated group, 35/321 participants had severe sequelae after one year, compared to $55 / 328$ in the control group (RR $0.65,95 \% \mathrm{Cl} 0.44$ to 0.96 ; see Analysis 2.3 and Figure 6) in favour of treatment with plasma exchange.

Figure 6. Forest plot of comparison: Plasma exchange compared to sham exchange or supportive treatment for Guillain-Barré syndrome, outcome: 2.3 Having or not severe motor sequelae after 1 year.

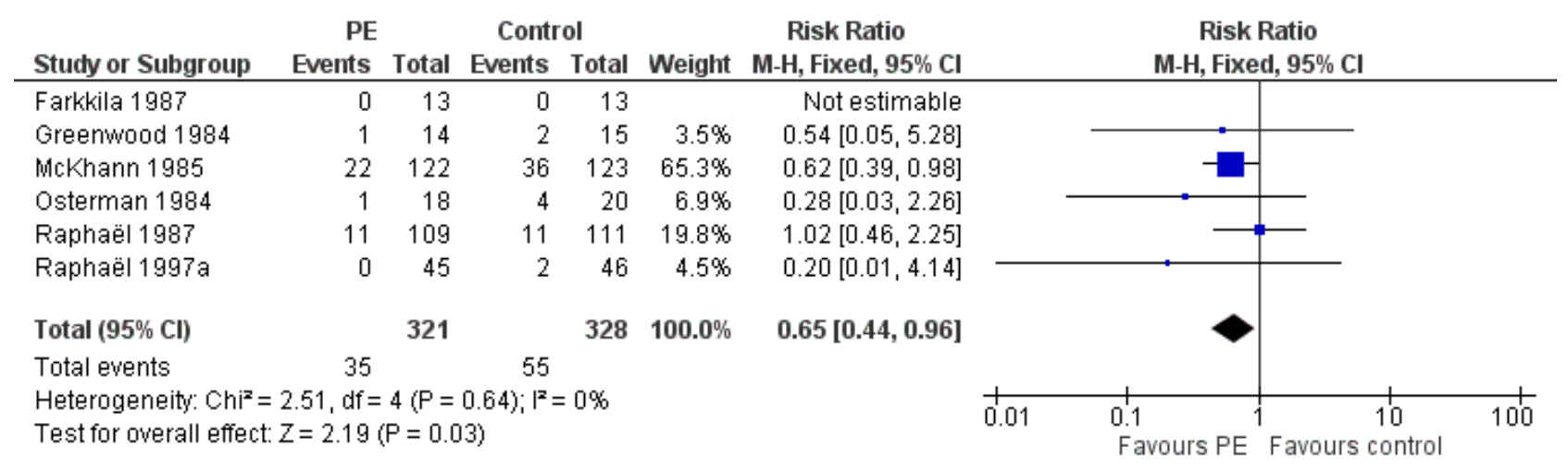

\section{Relapses after six months to one year}

Six trials reported data on relapses after six months to one year $(N=649)$. None of these studies gave the time elapsed between randomisation and relapse. In the treated group, 13/321 participants relapsed within the follow-up period (six months to one year), significantly more than the number who relapsed in the control group, which was $4 / 328$ (RR $2.89,95 \% \mathrm{Cl} 1.05$ to 7.93 ; Analysis 2.4 and Summary of findings for the main comparison).

\section{Complications}

Three trials $\mathrm{N}=556$ ) provided detailed information about serious adverse events during hospital stay (McKhann 1985; Raphaël 1987; Raphaël 1997a). Severe infectious events occurred in 93/276 participants in the treated group compared to $104 / 280$ in the control group (RR $0.91,95 \% \mathrm{Cl} 0.73$ to 1.13 ; Analysis 3.1). Fifty-two out of 276 participants in the treated group had blood pressure instability compared to 60/280 participants in the control group (RR $0.88,95 \% \mathrm{Cl} 0.64$ to 1.22 ; Analysis 3.2). Cardiac arrhythmias occurred in 58/276 participants in the treated group compared to $79 / 280$ participants in the control group (RR $0.75,95 \% \mathrm{Cl} 0.56$ to 1.00; Analysis 3.3). Four out of 276 participants had a pulmonary embolus in the treated group and 4/280 participants in the control group (RR 1.01, 95\% Cl 0.26 to 4.00; Analysis 3.4).

\section{Discontinuation of plasma exchange}

In two studies ( $N=67$ ), none of the participants allocated to plasma exchange had to discontinue the treatment Farkkila 1987; Osterman 1984). In Greenwood 1984 ( $\mathrm{N}=29$ ), 2/14 participants discontinued plasma exchange. In McKhann 1985 ( $N=245)$, $12 / 122$ participants had to discontinue plasma exchange, including three participants who refused to pursue the treatment. Nine participants discontinued plasma exchange because complications occurred. In Raphaël 1987 ( $\mathrm{N}=220$ ), 16/109 participants discontinued plasma exchange because of complications. In

Raphaël 1997a ( $\mathrm{N}=91$ ), 2/45 participants discontinued plasma exchange owing to complications.

\section{Subgroup analyses}

Younger and older

We found no study that had included children under 10 years old. Only one trial specifically addressed the issue of age, analysed as a continuous variable (McKhann 1985). In this study, although age was shown to be an independent prognostic factor, plasma exchange had a statistically significant beneficial effect over and above age.

\section{More severely or less severely affected}

Less severely affected people with GBS were defined as those who could walk at inclusion. Only one trial was designed to evaluate the effects of plasma exchange in people with GBS who could walk at randomisation (Raphaël 1997a). In this study, 91 participants were randomised to receive two plasma exchanges $(\mathrm{N}=45)$ or only supportive care $(N=46)$. This study showed a significant difference between the two groups in favour of treatment with plasma exchange for almost all outcome measures (see Data and analyses). In a second trial $(\mathrm{N}=220)$ only 10 participants could walk unaided at inclusion: three in the control group and seven in the treated group (Raphaël 1987). Separate data for this subset of participants were not available.

Trial authors defined more severely affected people with GBS as those on a ventilator at inclusion. Three trials provided separate analyses for the subset of participants on ventilator at randomisation, for a total of 103 ventilator-dependent participants (Farkkila 1987; McKhann 1985; Raphaël 1987). In Farkkila 1987, one of four participants in the treated group died compared to none of three in the control group. The mean ( \pm SD) time on ventilator was slightly shorter in the treated group compared to the 
control group ( $11.7 \pm 12.2$ days versus $15.3 \pm 6.1$ days). Three out of four participants in the treated group recovered full muscular strength after one year compared to all three participants in the control group. The two other trials defined the subgroup analysis of ventilator-dependent participants a priori and the sample size of the population was far more acceptable. In McKhann 1985, there were 57 ventilator-dependent participants at randomisation in the treated group and 52 in the control group. Fifty per cent of participants in the treated group had improved by one or more disability grades after one month, compared to $35 \%$ in the control group $(P=0.08)$. There was 0.8 grade improvement in the treated group compared to 0.1 in the control group $(P<0.001)$. The median time to recover walking unaided was shortened in the treated group compared to the control group (97 days versus 169 days, $P<0.01)$. Severe sequelae occurred in $26 \%$ of the treated group compared to $42 \%$ of the control group $(P=0.06)$. In Raphaël 1987 , 39 participants were ventilator dependent at randomisation in the treated group and 43 participants were ventilator dependent in the control group. The median time to onset of motor recovery was significantly shortened in the treated group compared to the control group ( 8 days versus 15 days, $P<0.005$ ), as well as the time to recover walking with aid ( 50 days versus 76 days, $P<0.05$ ).

\section{Having or not having documented relevant sensory deficit on routine} neurological examination (symptoms alone were ignored)

None of the studies provided data to allow estimation of effects of plasma exchange in the subsets of participants with or without sensory deficit.

Having or not having a history of diarrhoea (gastroenteritis) within the six weeks before the onset of neuropathic symptoms

None of the studies provided data to allow estimation of the effects of plasma exchange in the subset of participants with a history of gastroenteritis.

\section{Time from onset of neuropathy to start of treatment ( 7 days or less after onset, more than $\mathbf{7}$ up to $\mathbf{1 4}$ days after onset, and more than 14 days after onset)}

Two trials $(\mathrm{N}=465)$ provided separate analyses for the subset of participants based on length of illness before randomisation (McKhann 1985; Raphaël 1987). Namely, separate analyses were given for the subset of participants with GBS who had a length of illness of seven days or less, and for participants with a length of illness of more than seven days before randomisation. Neither study gave separate results for participants randomised after 14 days after onset. In McKhann 1985 ( $\mathrm{N}=245$ ), the number of participants with a length of illness before randomisation of seven days or less was not given. The median time to improve one or more disability grades was significantly shortened in the treated group compared to the control group both for the subset of participants randomised within seven days ( 23 days versus 68 days, $P<0.01$ ) and for the subset of participants randomised after seven days up to 30 days ( 18 days versus 37 days, $P=0.01$ ). The median time to walk without assistance was shortened in the treated group by 40 days for participants randomised before seven days $(P<$ 0.05 ) and by 35 days for those randomised between days seven and $30(\mathrm{P}<0.05)$. In Raphaël $1987(\mathrm{~N}=220)$, there were 158 participants randomised within seven days and 62 participants randomised after seven days. The median time to onset of motor recovery was significantly shortened in the treated group compared to the control group, both for the subset of participants randomised within seven days ( 7 days versus 13 days, $P<0.0001$ ) and for the subset of participants randomised after seven days up to 14 days ( 6 days versus 13 days, $P<0.005$ ). The median time to recover walking with assistance was also shortened in the plasma exchange group compared to the control group, for the subset of participants randomised within seven days ( 35 days versus 45 days, $P<0.05$ ). In the subset of participants randomised after seven days (up to 14 days), the median time to recover walking with aid was not significantly different ( 23 days versus 39 days, $\mathrm{P}<0.1$ ).

\section{Number of plasma exchanges}

Only two studies $(N=465)$ were designed to evaluate the appropriate number of plasma exchanges (Raphaël 1997b; Raphaël 1997c). In Raphaël 1997b, 304 people with GBS who could not stand unaided and who did not need respiratory assistance were randomised to receive either four $(N=155)$ or two $(N=149)$ sessions of plasma exchange. This trial showed that, compared to the two-sessions plasma exchange arm, in the four-sessions plasma exchange arm the median time to walk with aid (20 days versus 24 days, $P=0.04$ ) and the median time on the ventilator (15 days versus 37 days, $P=0.005$ ) were shortened. Similarly, the proportion of participants who recovered their full muscle strength after one year was higher in the four-session plasma exchange arm compared to the two-session plasma exchange arm (64\% versus $48 \%, \mathrm{P}=0.006$ ). In the four-session plasma exchange arm, a slightly higher proportion of participants had blood pressure instability (29\% versus $18 \%, P=0.04)$ or haematomas at venepuncture sites $(15 \%$ versus $6 \%, P=0.02)$ than in the two-session plasma exchange arm. In Raphaël 1997c, 161 ventilator-dependent GBS participants were randomised to receive either six or four sessions of plasma exchange. There was no significant difference between the two arms in any outcome measure, except for the proportion of participants with systolic blood pressure instability, which was significantly higher in the six-session plasma exchange arm (46\% versus $26 \%, P=0.001$ ).

\section{Separation technique: filtration or centrifugation (i.e. continuous or} discontinuous)

We found two studies $(\mathrm{N}=465)$ that addressed the issue of the technique for plasmapheresis, which is plasma exchange with a continuous flow machine versus an intermittent flow machine and cell separation versus filtration technique (McKhann 1985; Raphaël 1987). The results for these comparisons were published in subsequent papers (McKhann 1988; Raphaël 1992). In McKhann 1985 ( $N=245)$, in the subset of participants who received plasma exchange with continuous flow machines, a higher proportion of participants improved by one or more grades after one month than participants on intermittent flow machines (64\% versus $51 \%, \mathrm{P}<$ 0.01 ). The median time to improve by one grade was shortened in the subset of participants treated with continuous flow machines compared to those treated with intermittent flow machines (17 days versus 28 days, $\mathrm{P}<0.001$ ). The median time to reach unaided walking was also shortened ( 48 days versus 62 days, $P<0.01$ ). The authors could not find any other factor that might have explained the observed difference between the two techniques; it could not be explained by the volume of plasma exchanged or treatment on consecutive days. In Raphaël 1987 ( $\mathrm{N}=220), 71 \%$ of participants treated with the cell separation technique had full muscle strength recovery after one year compared to $69 \%$ in participants who were treated with the filtration technique $(P=0.80)$. This study did not show a significant difference for full muscle strength recovery after one year between participants treated with continuous machines 
and those treated with intermittent machines $(13 / 20$ versus $8 / 10, P$ $=0.68$ ).

\section{Type of replacement fluids: albumin plus gelatin or fresh frozen plasma}

We found only one study $(\mathrm{N}=220)$ that addressed the issue of the type of fluid replacement for plasma exchange (Raphaël 1987). The results were published in detail in two subsequent papers (Bouget 1993; Raphaël 1992). In this study, 57 participants were randomly allocated to receive plasma exchange with albumin and gelatin as replacement fluids and 52 received plasma exchange with fresh frozen plasma as the replacement fluid. The trial authors did not find any significant difference between the two arms in any of the outcomes. During plasma exchange, the decreases in fibrinogen (63\% versus $35 \%$ ) and prothrombin (52\% versus $18 \%$ ) levels were greater in participants who received plasma exchange with albumin as replacement fluid than those who received plasma exchange with fresh frozen plasma $(P=0.0001)$. The trial authors found a higher rate of adverse events in sessions using fresh frozen plasma as replacement fluid than with albumin ( $46 \%$ versus $32 \%, P=0.008)$.

\section{Cost benefits}

Though we did not plan to assess this outcome, we found two studies ( $N=130)$ that addressed the issue of cost-effectiveness (Osterman 1984; Raphaël 1997a). Osterman 1984 reported that plasma exchange of the 17 surviving participants in the treated group saved more than 500 days in hospital, at an average cost of more than GBP 100 per day. Thus, it was estimated that plasma exchange saved a total of GBP 50,000 while the total cost of plasma exchange was GBP 2000 per person, which is GBP 38,000 for the 18 participants of the treated group. In the second study, a costeffectiveness analysis was separately reported (Espérou 2000). In this study, for people with GBS who could stand unaided (disability grade 0 to 3), the total cost was estimated at EUR 20,876 in the two plasma exchange groups compared to EUR 38,877 in the control group. For participants who could not stand, the total cost was estimated at EUR 56,335 in the four-session plasma exchange arm compared to EUR 78,293 in the two-session plasma exchange arm. Finally, in people who were ventilator dependent, the total cost was estimated at EUR 55,983 in the six-session plasma exchange arm compared to EUR 53,221 in the four-session plasma exchange arm.

\section{DISCUSSION}

\section{Summary of main results}

According to moderate quality evidence, plasma exchange improved the majority of outcomes compared to supportive care alone. The time to recover walking with aid, the time to recover walking unaided and the time to improve by one or more disability grades were all shortened by plasma exchange. After four weeks, the combined data from three studies accounting for 349 participants showed that plasma exchange significantly improved the proportion of people with GBS who recovered the ability to walk with assistance. In addition, after four weeks, the combined data from five studies with 623 participants showed that plasma exchange significantly increased the number of participants being improved by one or more disability grade and the mean grade improvement. Plasma exchange shortened the time on ventilator and the proportion of ventilator-dependent participants was significantly decreased. During the hospital stay, plasma exchange did not alter the risk of severe infections or cardiovascular instability, but did significantly reduce the risk of cardiac arrhythmias. Plasma exchange also had longer-term benefits. It increased significantly the number of participants who had recovered full muscle strength and decreased the proportion of participants with severe motor sequelae after one year. However, the RR of relapsing was slightly increased by plasma exchange, which should be taken into account when arranging follow-up.

Plasma exchange had to be discontinued in $0 \%$ to $14 \%$ of participants in the various trials.

Trials suggested that the appropriate number of plasma exchanges is four sessions for people with moderate to severe GBS (Raphaël 1997a; Raphaël 1997b) and two sessions for those with mild GBS (Raphaël 1997c).

The results from one study suggested that plasma exchange might be better performed with continuous flow machines rather than with intermittent machines (McKhann 1985; McKhann 1988). However, these results were not confirmed in another study (Raphaël 1987; Raphaël 1992). In these studies participants were not randomised to receive one or other of these plasma exchange techniques.

The results of one trial (Raphaël 1987), in which participants were randomised to one or another fluid replacement strategy, suggested that albumin plus gelatin (or alternatively colloids or crystalloids) should be used rather than fresh frozen plasma. Indeed, similar efficacy was shown with each fluid replacement strategy while the risk of disease transmission may be higher with fresh frozen plasma.

Cost analyses derived from two studies showed a reduction of total costs in people with GBS treated by plasma exchange (Espérou 2000; Osterman 1984).

\section{Overall completeness and applicability of evidence}

We found no randomised trial that had assessed the efficacy of plasma exchange in children under 12 years old. For people older than 12 years with GBS, plasma exchange efficacy and tolerance may not be altered by age. According to McKhann 1985, plasma exchange may be more efficacious when performed within seven days of onset of motor deficit rather than later. Nevertheless in the same trial, people with GBS benefited from plasma exchange up to 30 days after disease onset.

The beneficial effect of plasma exchange was observed regardless of the severity of illness. For people with mild GBS, we found only one trial that had evaluated plasma exchange versus supportive care (Raphaël 1997a). This was a large RCT with a low risk of bias. The study provided results showing qualitatively and quantitatively similar benefit from plasma exchange to that observed in the various trials that had studied moderate and severe GBS. For people with severe GBS who were ventilator dependent, three trials provided data, which showed that participants from this particular subset also benefit from plasma exchange.

\section{Quality of the evidence}

For the primary outcome and most of the secondary outcomes we graded the quality of evidence as moderate, downgraded from high because all trials lacked blinding. 


\section{Potential biases in the review process}

In this review, we performed a comprehensive search of the literature with no restriction for language, so that there was a very limited risk that we missed important trials. According to the primary objective of this systematic review, only the trials that compared plasma exchange to supportive care alone, or that compared different modalities of plasma exchange, i.e. doses, types of fluids, or separation techniques, were included. Among the six relevant trials included in this review, three were large-scale multicentre trials with low risks of bias. We considered pooling the results of these trials in a meta-analysis acceptable. Participant blinding was never done as all investigators from the various trials agreed that sham plasma exchange is not ethical in people with GBS. Two studies made an effort to obtain assessment of outcomes by blinded observers (McKhann 1985; Osterman 1984).

Except for the studies by the French cooperative group, only published data were available. Consequently, we were unable to evaluate several outcome measures proposed in the protocol for this review. This was particularly the case for the primary end point, time to recover walking with aid (disability grade 3 ), an outcome of great interest to clinicians. The outcome 'change of one disability grade point at four weeks' was chosen as the primary outcome in many of the trials included in this meta-analysis, and was available in all trials. Thus, it was upgraded to the first secondary outcome for this review. We chose to convert outcome measures that corresponded to censored data into dichotomous variables, that is to say the presence or absence of a particular event or feature after four weeks or after one year.

\section{Agreements and disagreements with other studies or reviews}

The findings from this review are consistent with the recommendations from evidence-based guidelines for the use of plasmapheresis in neurologic disorders established by the American Academy of Neurology in 2011 (Cortese 2011). We are not aware of more recent guidelines.

Following the demonstration of benefit from plasma exchange, IVIg was introduced as an alternative treatment (Van der Meché 1992). Comparison of plasma exchange and IVIg in two randomised trials suggests that both have similar effects (PSGBS Group 1997; Van der
Meché 1992). A Cochrane systematic review of IVIg (Hughes 2014) and an umbrella review, incorporating the results of this review and those of IVIg and corticosteroids, agreed that IVIg and plasma exchange have equivalent efficacy in GBS (Hughes 2007).

\section{AUTHORS' CONCLUSIONS}

\section{Implications for practice}

Moderate-quality evidence accumulated from six trials uniformly supports the efficacy of plasma exchange in GBS assessed after four weeks or one year. This has been achieved without an increase in serious adverse events. According to one small trial, two sessions of plasma exchange was significantly superior to none in mild GBS. In one trial in moderate and severe GBS, four sessions were significantly superior to two. Non-randomised evidence showed that there is no significant difference in efficacy between continuous and intermittent flow plasma exchange machines. According to one trial albumin with colloids or crystalloids as replacement solutions are not significantly different in efficacy from fresh frozen plasma but are associated with significantly fewer adverse events. Non-randomised evidence showed that plasma exchange started seven days or less after the onset of neuropathy was more efficacious than plasma exchange started later. However, plasma exchange started between seven and 30 days after disease onset was more efficacious than no plasma exchange. There was a small but significant increase in the risk of relapse during the first six to 12 months after onset in people treated with plasma exchange compared with those were not treated.

\section{Implications for research}

The role of plasma exchange for treating GBS in children under 12 years old and in people with a duration of disease more than 30 days before treatment remain to be evaluated.

\section{ACKNOWLEDGEMENTS}

This project was supported by the National Institute for Health Research (NIHR) via Cochrane Infrastructure funding to Cochrane Neuromuscular. The views and opinions expressed herein are those of the review authors and do not necessarily reflect those of the Systematic Reviews Programme, NIHR, National Health Service, or the Department of Health. Cochrane Neuromuscular is also supported by the MRC Centre for Neuromuscular Diseases. 


\section{REFERE N CE S}

\section{References to studies included in this review}

Farkkila 1987 \{published data only\}

Färkkilä M, Kinnunen E, Haapanen E, Livanainen M. Guillain Barré syndrome: quantitative measurement of plasma exchange therapy. Neurology 1987;37(5):837-40. [PUBMED: 3553986]

\section{Greenwood 1984 \{published data only\}}

Greenwood RJ, Newsom-Davis J, Hughes RAC, Aslan S, Bowden AN, Chadwick DW, et al. Controlled trial of plasma exchange in acute inflammatory polyradiculoneuropathy. Lancet 1984;1(8382):877-9. [PUBMED: 6143188]

\section{McKhann 1985 \{published data only\}}

The Guillain-Barré syndrome study group. Plasmapheresis and acute Guillain-Barré syndrome. Neurology 1985;35(8):1096-104. [PUBMED: 4022342]

\section{Osterman 1984 \{published data only\}}

Osterman PO, Fagius J, Lundemo G, Pihlstedt P, Pirskanen R, Siden A, et al. Beneficial effects of plasma exchange in acute inflammatory polyradiculoneuropathy. Lancet 1984;2(8415):1296-9. [PUBMED: 6150321]

\section{Raphaël 1987 \{published data only\}}

* French Cooperative Group on Plasma Exchange in GuillainBarré syndrome. Efficiency of plasma exchange in GuillainBarré syndrome: role of replacement fluids. Annals of Neurology 1987;22(6):753-61. [PUBMED: 2893583]

French Cooperative Group on Plasma Exchange in GuillainBarré syndrome. Plasma exchange in Guillain-Barré syndrome: one year follow-up. Annals of Neurology 1992;32(1):94-7. [PUBMED: 1642477]

\section{Raphaël 1997a \{published data only\}}

French Cooperative Group on Plasma Exchange in Guillain-Barré Syndrome. Appropriate number of plasma exchanges in Guillain-Barré Syndrome. Annals of Neurology 1997;41(3):298-306. [PUBMED: 9066350]

\section{Raphaël 1997b \{published and unpublished data\}} French Cooperative Group on Plasma Exchange in Guillain-Barré Syndrome. Appropriate number of plasma exchanges in Guillain-Barré Syndrome. Annals of Neurology 1997;41(3):298-306. [PUBMED: 9066350]

\section{Raphaël 1997c \{published and unpublished data\}}

French Cooperative Group on Plasma Exchange in Guillain-Barré Syndrome. Appropriate number of plasma exchanges in Guillain-Barré Syndrome. Annals of Neurology 1997;41(3):298-306. [PUBMED: 9066350]

\section{References to studies excluded from this review \\ de-Zoysa 1994 \{published data only\} \\ de-Zoysa NS, Jayaweera KK, Vaithianathan T. Manual plasmapheresis in the treatment of Guillain Barré syndrome. Journal of Clinical Apheresis 1994;9(2):147-50.}

\section{El Bayoumi 2011 \{published data only\}}

El-Bayoumi MA, El-Refaey AM, Abdelkader AM, El-Assmy MM, Alwakeel AA, El-Tahan HM. Comparison of intravenous immunoglobulin and plasma exchange in treatment of mechanically ventilated children with Guillain Barré Syndrome. A randomized study. Critical Care. 2011; Vol. 15:R164.

\section{Mendell 1985 \{published data only\}}

Mendell JR, Kissel JT, Kennedy MS, Sahenk Z, Grinvalsky HT, Pittman GL, et al. Plasma exchange and prednisone in GuillainBarré syndrome: a controlled randomised trial. Neurology 1985;35(11):1551-5.

\section{Morosetti 1994 \{published data only\}}

Morosetti M, Meloni C, Taccone Gallucci M, Rossini PM, Felicioni R, Palombo G, et al. Plasmapheresis versus plasma perfusion in acute Guillain-Barré syndrome. ASAIO Journal 1994;40(3):M638-42.

\section{Rock 1997 \{published data only\}}

Rock G. Pentastarch instead of albumin as replacement fluid for therapeutic plasma exchange. The Canadian Apheresis Group. Journal of Clinical Apheresis 1997;12(4):165-9.

Wollinsky 2001 \{published data only\}

Wollinsky KH, Hulser PJ, Brinkmeier H, Aulkemeyer P, Bossenecker W, Huber-Hartmann $\mathrm{KH}$, et al. CSF filtration is an effective treatment of Guillain Barré syndrome: a randomized clinical trial. Neurology 2001;57(5):774-80.

\section{Additional references}

\section{Asbury 1990}

Asbury AK, Cornblath DR. Assessment of current diagnostic criteria for Guillain-Barré syndrome. Annals of Neurology 1990;27 Suppl:S21-4.

\section{Bouget 1993}

Bouget J, Chevret S, Chastang C, Raphael JC. Plasma exchange morbidity in Guillain Barré syndrome: results from the French prospective, randomized, multicenter study. The French Cooperative Group. Critical Care Medicine 1993;21(5):651-8.

\section{Brettle 1978}

Brettle RP, Gross M, Legg NJ, Lockwood M, Pallis C. Treatment of acute polyneuropathy by plasma exchange. Lancet 1978;2(8099):1100.

\section{Consensus 1986}

Consensus Conference. The utility of therapeutic plasmapheresis for neurological disorders. Journal of the American Medical Association 1986;256(10):1333-7. 


\section{Cook 1971}

Cook SD, Dowling PC, Murray MR, Whitaker JN. Circulating demyelinating factors in acute idiopathic polyneuropathy. Archives of Neurology 1971;24(2):136-44.

\section{Cortese 2011}

Cortese I, Chaudhry V, So YT, Cantor F, Cornblath DR, RaeGrant A. Evidence-based guideline update: plasmapheresis in neurologic disorders: report of the Therapeutics and Technology Assessment Subcommittee of the American Academy of Neurology. Neurology 2011;76(3):294-300.

\section{Espérou 2000}

Espérou H, Jars Guincestre MC, Bolgert F, Raphael JC, DurandZaleski I, and the French Cooperative Group on Plasma Exchange in Guillain-Barré syndrome. Cost-effectiveness of plasma exchange therapy for the treatment of Guillain-Barré syndrome. Intensive Care Medicine 2000;26(8):1094-100.

\section{Farkkila 1992}

Farkkila M, Penttila P. Plasma exchange therapy reduces the nursing care needed in Guillain-Barré syndrome. Journal of Advanced Nursing 1992;17(6):672-5.

\section{GRADEpro 2008 [Computer program]}

Jan Brozek, Andrew Oxman, Holger Schünemann. GRADEpro. Version 3.2 for Windows. Jan Brozek, Andrew Oxman, Holger Schünemann, 2008.

\section{Harrison 1984}

Harrison BM, Hansen LA, Pollard JD, Mc Leod JG. Demyelination induced by serum from patients with Guillain-Barré syndrome. Annals of Neurology 1984;15(2):163-70.

\section{Higgins 2011}

Higgins JPT, Green S (editors). Cochrane Handbook for Systematic Reviews of Interventions Version 5.1.0 [updated March 2011]. The Cochrane Collaboration, 2011. Available from www.cochrane-handbook.org.

\section{Hughes 1978}

Hughes RAC, Newsom-Davis JM, Perkin GD, Pierce JM. Controlled trial of prednisolone in acute polyneuropathy. Lancet 1978;2(8104-5):750-3.

\section{Hughes 2007}

Hughes RA, Swan AV, Raphael JC, Annane D, Van Koningsveld, Van Doorn PA. Immunotherapy for Guillain-Barré syndrome: a systematic review. Brain 2007;130(Pt 9):2245-57.

\section{Hughes 2011}

Hughes RA, Pritchard J, Hadden RD. Pharmacological treatment other than corticosteroids, intravenous immunoglobulin and plasma exchange for Guillain Barré syndrome. Cochrane Database of Systematic Reviews 2011, Issue 3. [DOI: 10.1002/14651858.CD008630.pub2]

\section{Hughes 2014}

Hughes RA, Swan AV, Van Doorn PA. Intravenous immunoglobulin for Guillain-Barré syndrome. Cochrane
Database of Systematic Reviews 2014, Issue 9. [DOI:

10.1002/14651858.CD002063.pub6]

\section{Mark 1980}

Mark B, Hurwitz J, Olanow CW, Fay JW. Plasmapheresis in idiopathic inflammatory polyradiculoneuropathy. Neurology 1980;30(4):361.

\section{McKhann 1985b}

The Guillain-Barré Syndrome Study Group. The North American study of plasmapheresis in the Guillain-Barré syndrome. Journal of Clinical Apheresis 1985;2:315-20.

\section{McKhann 1988}

McKhann GM, Griffin JW, Cornblath DR, Mellits ED, Fisher RS, Quaskey SA, et al. Plasmapheresis and Guillain-Barré syndrome: analysis of prognostic factors and the effect of plasmapheresis. Annals of Neurology 1988;23(4):347-53.

\section{Mendell 1985b}

Mendell JR, Kissel JT, Kennedy MS, Sahenk Z, Grinvalsky HT, Pittman GL, et al. Plasma exchange and prednisone in acute inflammatory polyradiculoneuropathy: a controlled randomized trial. Journal of Clinical Apheresis 1985;2(4):332-42.

\section{Metral 1989}

Metral S, Raphaël JC, Hort-Legrand CL, Elkharrat D. Serum demyelinating activity and Guillain-Barre syndrome: favorable effect of plasma exchange [Activité démyélinisante sérique et syndrome de Guillain-Barré: effet favorable des échanges plasmatiques]. Revue Neurologique 1989;145(4):312-9.

\section{PSGBS Group 1997}

Plasma Exchange/Sandoglobulin Guillain-Barré Syndrome Trial Group. Randomised trial of plasma exchange, intravenous immunoglobulin, and combined treatments in Guillain-Barré syndrome. Lancet 1997;349(9047):225-30.

\section{Raphaël 1985}

Raphael JC, Chastang C, and the Cooperative French Group. Cooperative randomized trial of plasma exchange in GuillainBarré syndrome. Plasma Therapy and Transfusion Technology 1985;6:603-4.

\section{Raphaël 1986}

Raphael JC, Chastang C. Cooperative randomized trial of plasma exchange in the Guillain-Barré syndrome. Short term effects and comparison of diluted albumin and fresh frozen plasma. Life Support System 1986;4:329-31.

\section{Raphaël 1992}

French Cooperative Group on Plasma Exchange in GuillainBarré syndrome. Plasma exchange in Guillain-Barré syndrome: one-year follow-up. Annals of Neurology 1992;32(1):94-7.

\section{Raphaël 1996}

Raphaël JC, Chevret S, Jars-Guincestre MC, Chastang C, Gajdos PH. Treatment of Guillain-Barré syndrome by plasma exchange: proposal of a therapeutic strategy [Traitement du syndrome de Guillain-Barré par les échanges plasmatiques: 
proposition d'une stratégie thérapeutique]. Revue Neurologique 1996;152(5):359-64.

\section{RevMan 2014 [Computer program]}

The Nordic Cochrane Centre, The Cochrane Collaboration. Review Manager (RevMan). Version 5.3. Copenhagen: The Nordic Cochrane Centre, The Cochrane Collaboration, 2014.

\section{Ropper 1980}

Ropper AH, Shahani B, Huggins CE. Improvement in four patients with acute Guillain-Barré syndrome after plasma exchange. Neurology 1980;30:361.

\section{Schooneman 1981}

Schooneman F, Janot C, Streiff F, Gérard A, Dureux JB, Canton P, et al. Plasma exchange in Guillain-Barré syndrome ten cases. Plasmapheresis Therapy 1981;2:117-21.

\section{Shumak 1984}

Shumak KH, Rock GA. Therapeutic plasma exchange. New England Journal of Medicine 1984;310(1212):762-71.

\section{Sumner 1982}

Sumner A, Said G, Idy I, Metral S. Electrophysiological and morphological effects of the injection of Guillain-Barré sera in the sciatic nerve of the rat [Syndrome de Guillain-Barré. Effects electro-physiologiques du sérum humain introduit dans l'espace endoneural du nerf sciatique du rat. Résultats préliminaires]. Revue Neurologique 1982;138(1):17-24. [MEDLINE: 1982249353]

\section{Valbonesi 1981}

Valbonesi M, Garelli S, Mosconi L, Zerbi D, Celano I. Plasma exchange as a therapy for Guillain-Barré syndrome with immune complexes. Vox Sanguinis 1981;41:74-8.

\section{Van der Meché 1992}

Van der Meché FGA, Schmitz PIM, Dutch Guillain-Barré Study Group. A randomized trial comparing intravenous immune

\section{CHARACTERISTICS OF STUDIES}

Characteristics of included studies [ordered by study ID] globulin and plasma exchange in Guillain-Barré syndrome. New England Journal of Medicine 1992;326(17):1123-9.

\section{Visser 1999}

Visser LH, Schmitz PI, Meulstee J, Van Doorn PA, Van der Meché FG. Prognostic factors of Guillain-Barré syndrome after intravenous immunoglobulin or plasma exchange. Dutch Guillain-Barré Study Group. Neurology 1999;53(3):598-604.

\section{Willison 2016}

Willison HJ, Jacobs BC, Van Doorn PA. Guillain-Barré syndrome. Lancet 2016;388:717-27.

\section{Yuki 2012}

Yuki N, Hartung HP. Guillain-Barré syndrome. New England Journal of Medicine 2012;366(24):2294-304.

\section{References to other published versions of this review Raphael 2012}

Raphaël JC, Chevret S, Hughes RAC, Annane D. Plasma exchange for Guillain-Barré syndrome. Cochrane Database of Systematic Reviews 2012, Issue 7. [DOI: 10.1002/14651858.CD001798.pub2]

\section{Raphaël 2001}

Raphaël JC, Chevret S, Hughes RA, Annane D. Plasma exchange for Guillain-Barré syndrome. Cochrane Database of Systematic Reviews 2001, Issue 2. [DOI: 10.1002/14651858.CD001798]

\section{Raphaël 2002}

Raphaël JC, Chevret S, Hughes RAC, Annane D. Plasma exchange for Guillain-Barré syndrome. Cochrane Database of Systematic Reviews 2002, Issue 2. [DOI: 10.1002/14651858.CD001798]

* Indicates the major publication for the study

\section{Farkkila 1987}

\begin{tabular}{ll}
\hline Methods & RCT, single centre, open, parallel group \\
\hline Participants & $\begin{array}{l}\text { N }=29 \text {, acute GBS only } \\
\text { No mild forms }\end{array}$ \\
\hline Interventions & $\begin{array}{l}\text { Plasma exchange versus supportive care } \\
\text { 3 to } 5 \text { plasma exchange, } 3 \text { L per plasma exchange, diluted albumin }\end{array}$ \\
\hline Outcomes & Hand-grip force at 3 weeks after first plasma exchange \\
\hline Notes & - \\
\hline Risk of bias & \\
\hline \hline
\end{tabular}


Farkkila 1987 (Continued)

\begin{tabular}{|c|c|c|}
\hline Bias & Authors' judgement & Support for judgement \\
\hline $\begin{array}{l}\text { Random sequence genera- } \\
\text { tion (selection bias) }\end{array}$ & Unclear risk & $\begin{array}{l}\text { There is no description of the method used for generating the allocation se- } \\
\text { quence }\end{array}$ \\
\hline $\begin{array}{l}\text { Allocation concealment } \\
\text { (selection bias) }\end{array}$ & High risk & They used alternate allocation \\
\hline $\begin{array}{l}\text { Blinding (performance } \\
\text { bias and detection bias) } \\
\text { All outcomes }\end{array}$ & High risk & The trial was not blinded \\
\hline $\begin{array}{l}\text { Incomplete outcome data } \\
\text { (attrition bias) } \\
\text { All outcomes }\end{array}$ & Low risk & $\begin{array}{l}3 / 29 \text { participants ( } 1 \text { in the experimental arm and } 2 \text { in the control arm) were ex- } \\
\text { cluded }\end{array}$ \\
\hline $\begin{array}{l}\text { Selective reporting (re- } \\
\text { porting bias) }\end{array}$ & Unclear risk & $\begin{array}{l}\text { The authors did not provide the time to recover walking with aid or the pro- } \\
\text { portion of participants with } 1 \text { or more disability grades' improvement at } 1 \\
\text { month. The authors stated that the } 2 \text { groups were comparable after } 1 \text { year, but } \\
\text { did not provide any data }\end{array}$ \\
\hline Other bias & Unclear risk & $\begin{array}{l}\text { Problems with diagnostic criteria and } 3 \text { participants did not have GBS, } 1 \text { had } \\
\text { a form of relapsing polyradiculoneuritis and } 2 \text { other participants ( } 1 \text { in each } \\
\text { group) had poliomyelitis }\end{array}$ \\
\hline
\end{tabular}

Greenwood 1984

\begin{tabular}{ll}
\hline Methods & RCT, multicentre, open, parallel groups \\
\hline Participants & $\begin{array}{l}\mathrm{N}=29, \text { acute GBS only } \\
\text { All ages } \\
\text { No mild forms }\end{array}$ \\
\hline Interventions & Plasma exchange versus supportive care \\
& 5 plasma exchange in 5 days, $55 \mathrm{~mL} / \mathrm{kg}$ per plasma exchange \\
\hline Outcomes & Functional ability at 4 weeks after completion of treatment \\
\hline Notes & - \\
\hline
\end{tabular}

\section{Risk of bias}

\begin{tabular}{lll}
\hline Bias & Authors' judgement & Support for judgement \\
\hline $\begin{array}{l}\text { Random sequence genera- } \\
\text { tion (selection bias) }\end{array}$ & Low risk & Computer generated \\
\hline $\begin{array}{l}\text { Allocation concealment } \\
\text { (selection bias) }\end{array}$ & Low risk & Centralisation of the randomisation \\
\hline $\begin{array}{l}\text { Blinding (performance } \\
\text { bias and detection bias) } \\
\text { All outcomes }\end{array}$ & High risk & Trial was not blinded \\
\hline $\begin{array}{l}\text { Incomplete outcome data } \\
\text { (attrition bias) }\end{array}$ & Low risk & No loss to follow-up, intention-to-treat analysis \\
\hline
\end{tabular}


Greenwood 1984 (Continued)

All outcomes

Selective reporting (re- Low risk Data reported for all pre-specified outcomes
porting bias)

\begin{tabular}{ll}
\hline Other bias Low risk & $\begin{array}{l}\text { Explicit diagnostic criteria, explicit outcome criteria, no imbalance in baseline } \\
\text { characteristics between treatment arms }\end{array}$ \\
\hline
\end{tabular}

\section{McKhann 1985}

\begin{tabular}{ll}
\hline Methods & RCT, multicentre, open, parallel groups \\
\hline Participants & $\mathrm{N}=245$, acute GBS only \\
& $\begin{array}{l}\text { All ages } \\
\text { No mild forms }\end{array}$ \\
\hline Interventions & $\begin{array}{l}\text { Plasma exchange versus supportive care } \\
\text { 3 to } 5 \text { plasma exchange in } 5 \text { days, } 40 \mathrm{~mL} / \mathrm{kg} \text { per plasma exchange }\end{array}$ \\
\hline Outcomes & Functional ability at 4 weeks \\
\hline Notes & -
\end{tabular}

\section{Risk of bias}

\begin{tabular}{|c|c|c|}
\hline Bias & Authors' judgement & Support for judgement \\
\hline $\begin{array}{l}\text { Random sequence genera- } \\
\text { tion (selection bias) }\end{array}$ & Low risk & Computer generated \\
\hline $\begin{array}{l}\text { Allocation concealment } \\
\text { (selection bias) }\end{array}$ & Low risk & Centralisation of randomisation \\
\hline $\begin{array}{l}\text { Blinding (performance } \\
\text { bias and detection bias) } \\
\text { All outcomes }\end{array}$ & High risk & $\begin{array}{l}\text { Unblinded trial; nevertheless observer remained blinded, and centralised re- } \\
\text { view of case reports }\end{array}$ \\
\hline $\begin{array}{l}\text { Incomplete outcome data } \\
\text { (attrition bias) } \\
\text { All outcomes }\end{array}$ & Low risk & No loss to follow-up, intention- to-treat analysis \\
\hline $\begin{array}{l}\text { Selective reporting (re- } \\
\text { porting bias) }\end{array}$ & Low risk & Data reported for all pre-specified outcomes \\
\hline Other bias & Low risk & $\begin{array}{l}\text { Explicit diagnostic criteria, explicit outcome criteria, no imbalance in baseline } \\
\text { characteristics between treatment arms }\end{array}$ \\
\hline
\end{tabular}

\section{Osterman 1984}

\begin{tabular}{ll}
\hline Methods & RCT, multicentre, open, parallel groups \\
\hline Participants & $\mathrm{N}=38$, acute GBS only \\
& Adults only \\
\hline
\end{tabular}


Osterman 1984 (Continued)

No mild forms

\begin{tabular}{ll} 
Interventions & Plasma exchange versus supportive care \\
& 3 to 8 plasma exchanges in 7 to 10 days, 3 L per plasma exchange \\
\hline Outcomes & $\begin{array}{l}\text { Muscle weakness score from randomisation to } 6 \text { months } \\
\text { Functional ability at } 4 \text { weeks }\end{array}$
\end{tabular}

Notes

\section{Risk of bias}

\begin{tabular}{|c|c|c|}
\hline Bias & Authors' judgement & Support for judgement \\
\hline $\begin{array}{l}\text { Random sequence genera- } \\
\text { tion (selection bias) }\end{array}$ & High risk & Alternate randomisation \\
\hline $\begin{array}{l}\text { Allocation concealment } \\
\text { (selection bias) }\end{array}$ & High risk & Alternate randomisation \\
\hline $\begin{array}{l}\text { Blinding (performance } \\
\text { bias and detection bias) } \\
\text { All outcomes }\end{array}$ & High risk & $\begin{array}{l}\text { Non-blinded trial, nevertheless observers remained blinded, and centralised } \\
\text { review of case reports }\end{array}$ \\
\hline $\begin{array}{l}\text { Incomplete outcome data } \\
\text { (attrition bias) } \\
\text { All outcomes }\end{array}$ & Low risk & No loss to follow-up, intention-to-treat analysis \\
\hline $\begin{array}{l}\text { Selective reporting (re- } \\
\text { porting bias) }\end{array}$ & Low risk & Data reported for all pre-specified outcomes \\
\hline Other bias & Low risk & $\begin{array}{l}\text { Explicit diagnostic criteria, explicit outcome criteria, no imbalance in baseline } \\
\text { characteristics between treatment arms }\end{array}$ \\
\hline
\end{tabular}

Raphaël 1987

\begin{tabular}{ll}
\hline Methods & RCT, multicentre, open, parallel groups \\
\hline Participants & $\begin{array}{l}\mathrm{N}=220, \text { acute GBS only } \\
\text { Adults only } \\
\text { All forms }\end{array}$ \\
\hline Interventions & $\begin{array}{l}\text { Plasma exchange versus supportive care } \\
\text { 4 plasma exchange in } 8 \text { days, } 3 \text { litres per plasma exchange, diluted albumin or fresh frozen plasma }\end{array}$ \\
\hline Outcomes & Time to recover walking with assistance \\
\hline Notes &
\end{tabular}

\section{Risk of bias}

\begin{tabular}{lll}
\hline Bias & Authors' judgement & Support for judgement \\
\hline $\begin{array}{l}\text { Random sequence genera- } \\
\text { tion (selection bias) }\end{array}$ & Low risk & Computer generated \\
\hline & & \\
\hline
\end{tabular}


Raphaël 1987 (Continued)

\begin{tabular}{|c|c|c|}
\hline $\begin{array}{l}\text { Allocation concealment } \\
\text { (selection bias) }\end{array}$ & Low risk & Centralisation of randomisation \\
\hline $\begin{array}{l}\text { Blinding (performance } \\
\text { bias and detection bias) } \\
\text { All outcomes }\end{array}$ & High risk & $\begin{array}{l}\text { Non-blinded trial, nevertheless the authors used a centralised review of case } \\
\text { reports }\end{array}$ \\
\hline $\begin{array}{l}\text { Incomplete outcome data } \\
\text { (attrition bias) } \\
\text { All outcomes }\end{array}$ & Low risk & $4 \%$ lost to follow-up, intention-to-treat analysis \\
\hline $\begin{array}{l}\text { Selective reporting (re- } \\
\text { porting bias) }\end{array}$ & Low risk & Data reported for all pre-specified outcomes \\
\hline Other bias & Low risk & $\begin{array}{l}\text { Explicit diagnostic criteria, explicit outcome criteria, no imbalance in baseline } \\
\text { characteristics between treatment arms }\end{array}$ \\
\hline
\end{tabular}

Raphaël 1997a

\begin{tabular}{ll}
\hline Methods & RCT, multicentre, open, parallel groups \\
\hline Participants & $\begin{array}{l}\text { Adults only } \\
\text { Mild forms }\end{array}$ \\
\hline Interventions & $\begin{array}{l}\text { Plasma exchange versus supportive care } \\
2 \text { plasma exchange every other days, } 3 \text { L per plasma exchange, diluted albumin + gelatin }\end{array}$ \\
\hline Outcomes & Time to onset of motor recovery \\
\hline Notes & -
\end{tabular}

\section{Risk of bias}

\begin{tabular}{|c|c|c|}
\hline Bias & Authors' judgement & Support for judgement \\
\hline $\begin{array}{l}\text { Random sequence genera- } \\
\text { tion (selection bias) }\end{array}$ & Low risk & Computer generated \\
\hline $\begin{array}{l}\text { Allocation concealment } \\
\text { (selection bias) }\end{array}$ & Low risk & Centralisation of randomisation \\
\hline $\begin{array}{l}\text { Blinding (performance } \\
\text { bias and detection bias) } \\
\text { All outcomes }\end{array}$ & High risk & $\begin{array}{l}\text { Non-blinded trial, nevertheless the authors used a centralised review of case } \\
\text { reports }\end{array}$ \\
\hline $\begin{array}{l}\text { Incomplete outcome data } \\
\text { (attrition bias) } \\
\text { All outcomes }\end{array}$ & Low risk & No loss to follow-up, intention-to-treat analysis \\
\hline $\begin{array}{l}\text { Selective reporting (re- } \\
\text { porting bias) }\end{array}$ & Low risk & Data reported for all pre-specified outcomes \\
\hline Other bias & Low risk & $\begin{array}{l}\text { Explicit diagnostic criteria, explicit outcome criteria, no imbalance in baseline } \\
\text { characteristics between treatment arms }\end{array}$ \\
\hline
\end{tabular}


Raphaël 1997b

\begin{tabular}{ll}
\hline Methods & RCT, multicentre, open, parallel groups \\
\hline Participants & N $=304$, acute GBS only \\
& $\begin{array}{l}\text { Adults only } \\
\text { Moderate forms }\end{array}$ \\
\hline Interventions & 2 plasma exchange versus 4 plasma exchange, \\
& 3 L per plasma exchange, diluted albumin + gelatin, plasma exchange every other day \\
\hline Outcomes & Time to recover walking with assistance \\
\hline Notes & -
\end{tabular}

\section{Risk of bias}

\begin{tabular}{lll}
\hline Bias & Authors' judgement & Support for judgement \\
\hline $\begin{array}{l}\text { Random sequence genera- } \\
\text { tion (selection bias) }\end{array}$ & Low risk & Computer generated \\
\hline $\begin{array}{l}\text { Allocation concealment } \\
\text { (selection bias) }\end{array}$ & Low risk & Centralisation of randomisation \\
\hline $\begin{array}{l}\text { Blinding (performance } \\
\text { bias and detection bias) } \\
\text { All outcomes }\end{array}$ & High risk & $\begin{array}{l}\text { Non-blinded trial, nevertheless the authors used a centralised review of case } \\
\text { reports }\end{array}$ \\
\hline $\begin{array}{l}\text { Incomplete outcome data } \\
\text { (attrition bias) } \\
\text { All outcomes }\end{array}$ & Low risk & No loss to follow-up, intention-to-treat analysis \\
\hline $\begin{array}{l}\text { Selective reporting (re- } \\
\text { porting bias) }\end{array}$ & Low risk & Data reported for all pre-specified outcomes \\
\hline $\begin{array}{l}\text { Other bias } \\
\text { L }\end{array}$ & Low risk & $\begin{array}{l}\text { Explicit diagnostic criteria, explicit outcome criteria, no imbalance in baseline } \\
\text { characteristics between treatment arms }\end{array}$ \\
\hline
\end{tabular}

Raphaël 1997c

\begin{tabular}{ll}
\hline Methods & RCT, multicentre, open, parallel groups \\
\hline Participants & $\begin{array}{l}\mathrm{N}=161 \text {, acute GBS only } \\
\text { Adults only } \\
\text { Severe (mechanically ventilated) forms }\end{array}$ \\
\hline Interventions & $\begin{array}{l}\text { 4 plasma exchange versus } 6 \text { plasma exchange } \\
3 \text { litres per plasma exchange, diluted albumin + gelatin, plasma exchange every other day }\end{array}$ \\
\hline Outcomes & Time to recover walking with assistance \\
\hline Notes & -
\end{tabular}

\section{Risk of bias}

Plasma exchange for Guillain-Barré syndrome (Review) 
Raphaël 1997c (Continued)

\begin{tabular}{lll} 
Bias & Authors' judgement & Support for judgement \\
\hline $\begin{array}{l}\text { Random sequence genera- } \\
\text { tion (selection bias) }\end{array}$ & Low risk & Computer generated \\
\hline $\begin{array}{l}\text { Allocation concealment } \\
\text { (selection bias) }\end{array}$ & Low risk & Centralisation of randomisation \\
\hline $\begin{array}{l}\text { Blinding (performance } \\
\text { bias and detection bias) } \\
\text { All outcomes }\end{array}$ & High risk & $\begin{array}{l}\text { Non-blinded trial, nevertheless the authors used a centralised review of case } \\
\text { reports }\end{array}$ \\
\hline $\begin{array}{l}\text { Incomplete outcome data } \\
\text { (attrition bias) }\end{array}$ & Low risk & No loss to follow-up, intention-to-treat analysis \\
$\begin{array}{l}\text { All outcomes } \\
\text { Selective reporting (re- } \\
\text { porting bias) }\end{array}$ & Low risk & Data reported for all pre-specified outcomes \\
\hline $\begin{array}{l}\text { Other bias } \\
\text { L }\end{array}$ & Low risk & $\begin{array}{l}\text { Explicit diagnostic criteria, explicit outcome criteria, no imbalance in baseline } \\
\text { characteristics between treatment arms }\end{array}$ \\
\hline
\end{tabular}

GBS: Guillain-Barré syndrome; RCT: randomised controlled trial.

Characteristics of excluded studies [ordered by study ID]

\begin{tabular}{ll}
\hline Study & Reason for exclusion \\
\hline de-Zoysa 1994 & No control group \\
\hline El Bayoumi 2011 & $\begin{array}{l}\text { Plasma exchange was compared to intravenous immunoglobulin in children being ventilated for } \\
\text { severe GBS }\end{array}$ \\
\hline Mendell 1985 & $\begin{array}{l}\text { The study evaluated the effects of the combination of plasma exchange and corticosteroids versus } \\
\text { supportive care and not of plasma exchange alone versus supportive care }\end{array}$ \\
\hline Morosetti 1994 & Plasma exchange was compared to plasma perfusion and not to conservative treatment alone \\
\hline Rock 1997 & $\begin{array}{l}\text { The study population was made up of participants with GBS and participants with myasthenia } \\
\text { gravis. Separate data for participants with GBS could not be obtained }\end{array}$ \\
\hline Wollinsky 2001 & $\begin{array}{l}\text { Plasma exchange was compared to cerebrospinal fluid filtration and not to conservative treatment } \\
\text { alone }\end{array}$ \\
\hline
\end{tabular}

GBS: Guillain-Barré syndrome.

\section{DATA AND ANALYSES}


Comparison 1. Plasma exchange compared to sham exchange or supportive treatment for Guillain-Barré syndrome: four-week end points

\begin{tabular}{|c|c|c|c|c|}
\hline Outcome or subgroup title & No. of studies & $\begin{array}{l}\text { No. of partici- } \\
\text { pants }\end{array}$ & Statistical method & Effect size \\
\hline 1 Walking with aid after 4 weeks & 3 & 349 & $\begin{array}{l}\text { Risk Ratio (M-H, Fixed, 95\% } \\
\mathrm{Cl})\end{array}$ & $1.60[1.19,2.15]$ \\
\hline $\begin{array}{l}2 \text { Improvement by } 1 \text { grade after } 4 \\
\text { weeks }\end{array}$ & 5 & 623 & $\begin{array}{l}\text { Risk Ratio (M-H, Fixed, 95\% } \\
\mathrm{Cl} \text { ) }\end{array}$ & $1.64[1.37,1.96]$ \\
\hline $\begin{array}{l}3 \text { Mean disability grade improve- } \\
\text { ment after } 4 \text { weeks }\end{array}$ & 4 & 585 & $\begin{array}{l}\text { Mean Difference (IV, Fixed, } \\
95 \% \mathrm{CI})\end{array}$ & $-0.89[-1.14,-0.63]$ \\
\hline 4 Walking without aid after 4 weeks & 3 & 349 & $\begin{array}{l}\text { Risk Ratio (M-H, Fixed, 95\% } \\
\mathrm{Cl} \text { ) }\end{array}$ & $1.72[1.06,2.79]$ \\
\hline $\begin{array}{l}5 \text { Mechanically ventilated after } 4 \\
\text { weeks }\end{array}$ & 5 & 623 & $\begin{array}{l}\text { Risk Ratio (M-H, Fixed, 95\% } \\
\mathrm{Cl})\end{array}$ & $0.53[0.39,0.74]$ \\
\hline 6 Duration of mechanical ventilation & 2 & 132 & $\begin{array}{l}\text { Mean Difference (IV, Fixed, } \\
95 \% \mathrm{CI} \text { ) }\end{array}$ & $-5.09[-12.94,2.76]$ \\
\hline
\end{tabular}

Analysis 1.1. Comparison 1 Plasma exchange compared to sham exchange or supportive treatment for Guillain-Barré syndrome: four-week end points, Outcome 1 Walking with aid after 4 weeks.

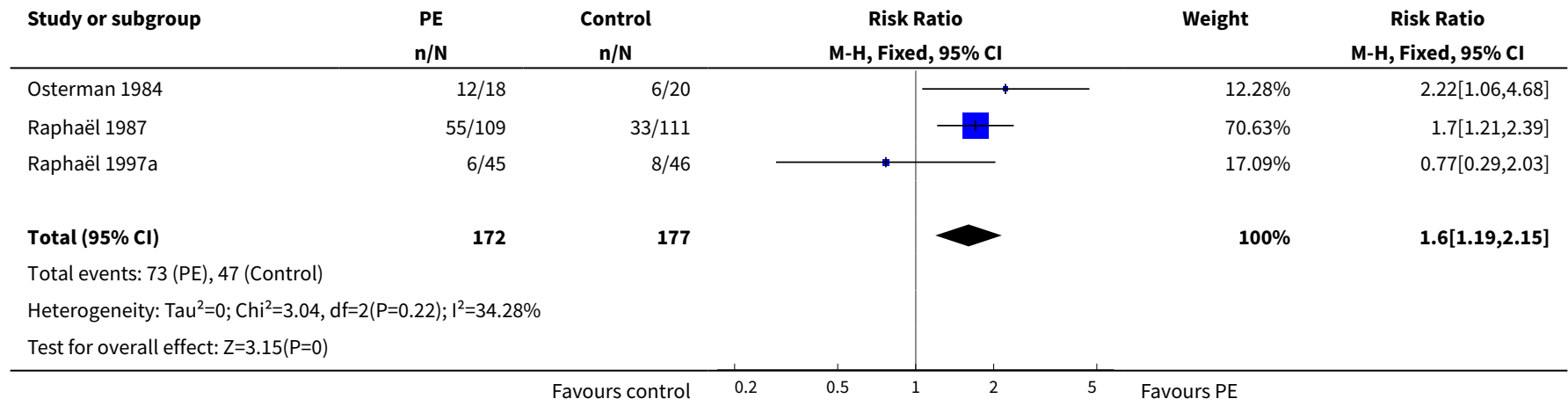

Analysis 1.2. Comparison 1 Plasma exchange compared to sham exchange or supportive treatment for Guillain-Barré syndrome: four-week end points, Outcome 2 Improvement by 1 grade after 4 weeks.

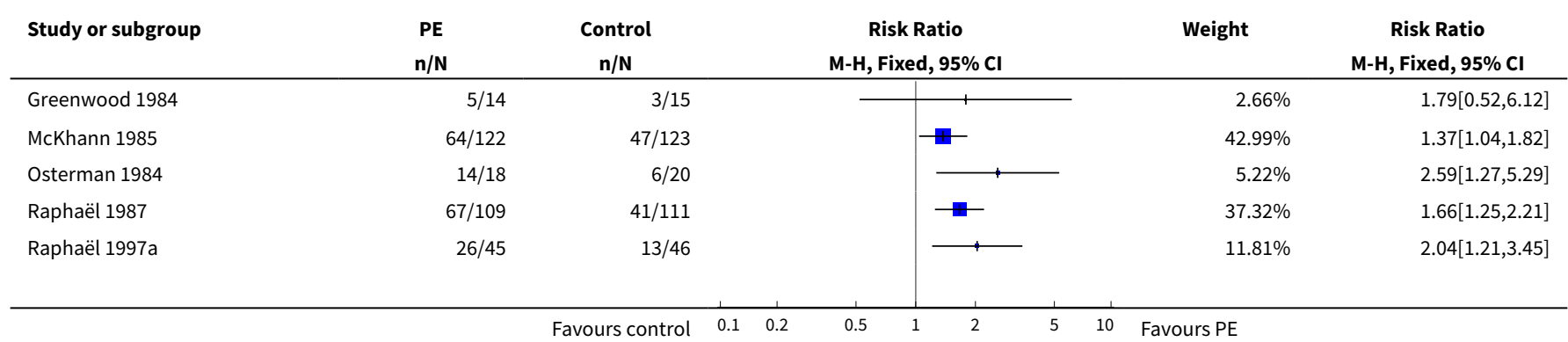




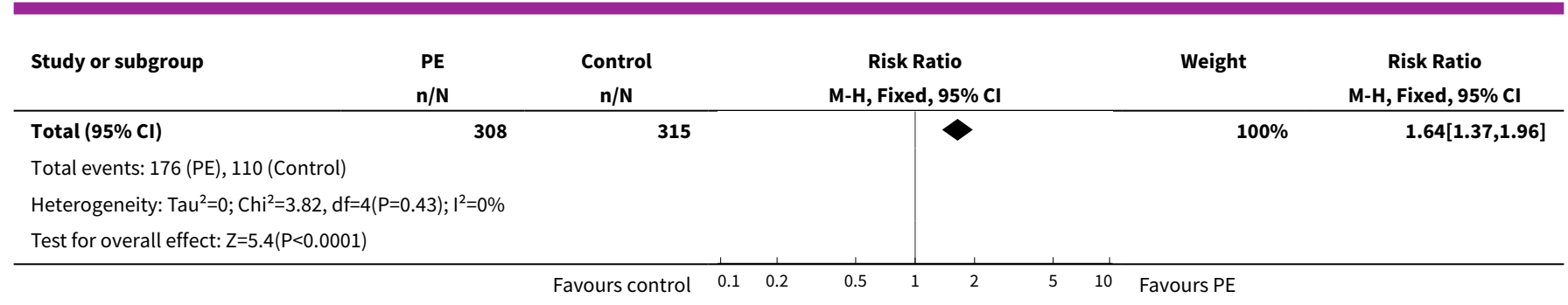

Analysis 1.3. Comparison 1 Plasma exchange compared to sham exchange or supportive treatment for Guillain-Barré syndrome: four-week end points, Outcome 3 Mean disability grade improvement after 4 weeks.

\begin{tabular}{|c|c|c|c|c|c|c|c|c|}
\hline \multirow{3}{*}{$\begin{array}{l}\text { Study or subgroup } \\
\text { Greenwood } 1984\end{array}$} & \multicolumn{2}{|c|}{ PE } & \multicolumn{2}{|c|}{ Control } & \multirow{2}{*}{\multicolumn{2}{|c|}{$\begin{array}{c}\text { Mean Difference } \\
\text { Fixed, } 95 \% \mathrm{Cl}\end{array}$}} & \multirow[t]{2}{*}{ Weight } & \multirow{2}{*}{$\begin{array}{c}\text { Mean Difference } \\
\text { Fixed, } 95 \% \mathrm{Cl}\end{array}$} \\
\hline & $\mathbf{N}$ & Mean(SD) & $\mathbf{N}$ & $\operatorname{Mean}(\mathrm{SD})$ & & & & \\
\hline & 14 & $-0.6(1.4)$ & 15 & $-0.3(1.1)$ & $\longrightarrow$ & + & $8.12 \%$ & $-0.37[-1.25,0.51]$ \\
\hline McKhann 1985 & 122 & $-1.1(1.9)$ & 123 & $-0.4(1.6)$ & $\longrightarrow$ & & $32.21 \%$ & $-0.7[-1.14,-0.26]$ \\
\hline Raphaël 1987 & 109 & $-1.3(1.9)$ & 111 & $-0.3(1.6)$ & $\longrightarrow$ & & $28.89 \%$ & $-1.01[-1.48,-0.54]$ \\
\hline Raphaël 1997a & 45 & $-1(1.2)$ & 46 & $0.1(1)$ & $\mp$ & & $30.78 \%$ & $-1.1[-1.55,-0.65]$ \\
\hline \multicolumn{9}{|c|}{ Heterogeneity: $\mathrm{Tau}^{2}=0 ; \mathrm{Chi}^{2}=3.1, \mathrm{df}=3(\mathrm{P}=0.38) ; \mathrm{I}^{2}=3.28 \%$} \\
\hline \multicolumn{9}{|c|}{ Test for overall effect: $Z=6.89(P<0.0001)$} \\
\hline
\end{tabular}

Analysis 1.4. Comparison 1 Plasma exchange compared to sham exchange or supportive treatment for Guillain-Barré syndrome: four-week end points, Outcome 4 Walking without aid after 4 weeks.

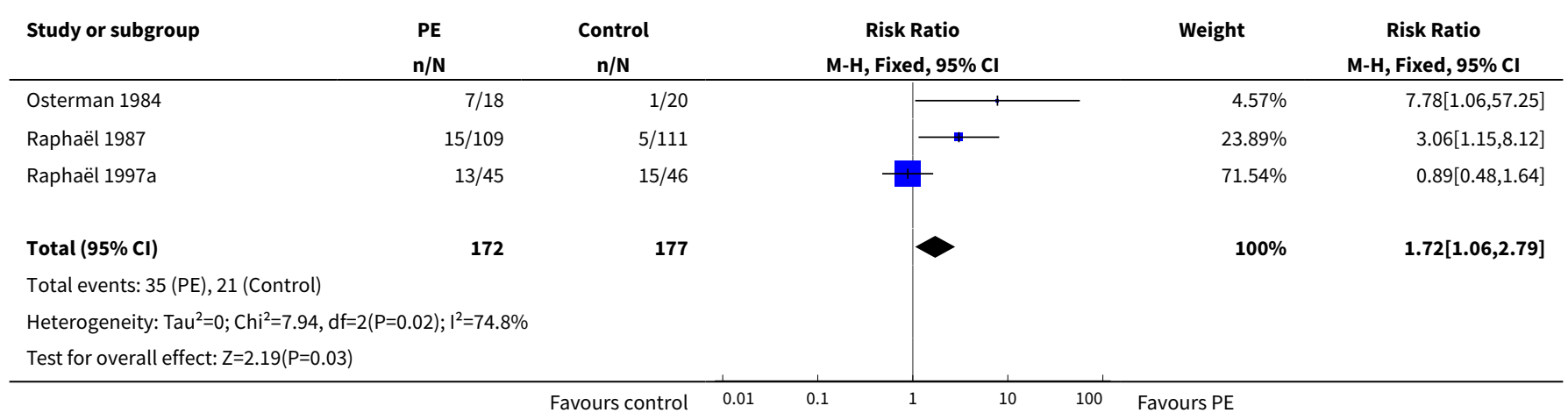

Analysis 1.5. Comparison 1 Plasma exchange compared to sham exchange or supportive treatment for Guillain-Barré syndrome: four-week end points, Outcome 5 Mechanically ventilated after 4 weeks.

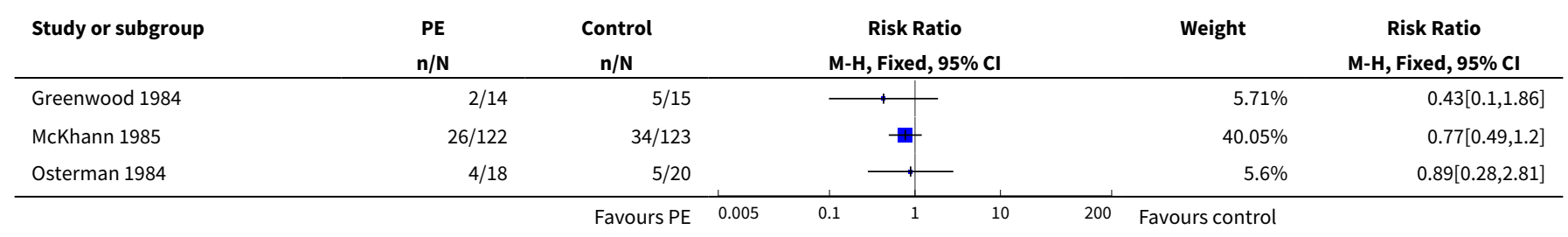




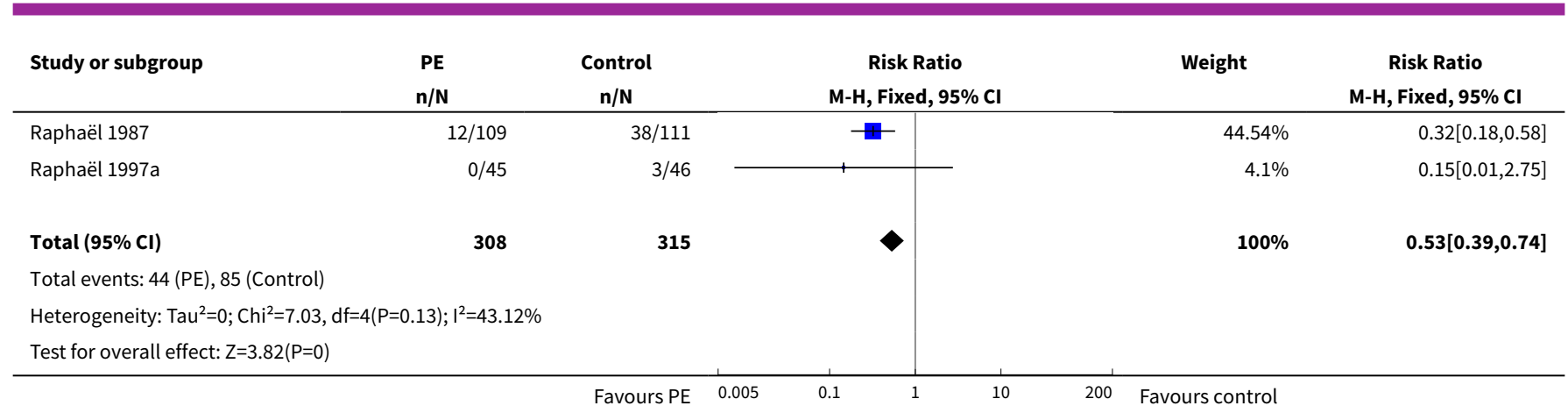

Analysis 1.6. Comparison 1 Plasma exchange compared to sham exchange or supportive treatment for Guillain-Barré syndrome: four-week end points, Outcome 6 Duration of mechanical ventilation.

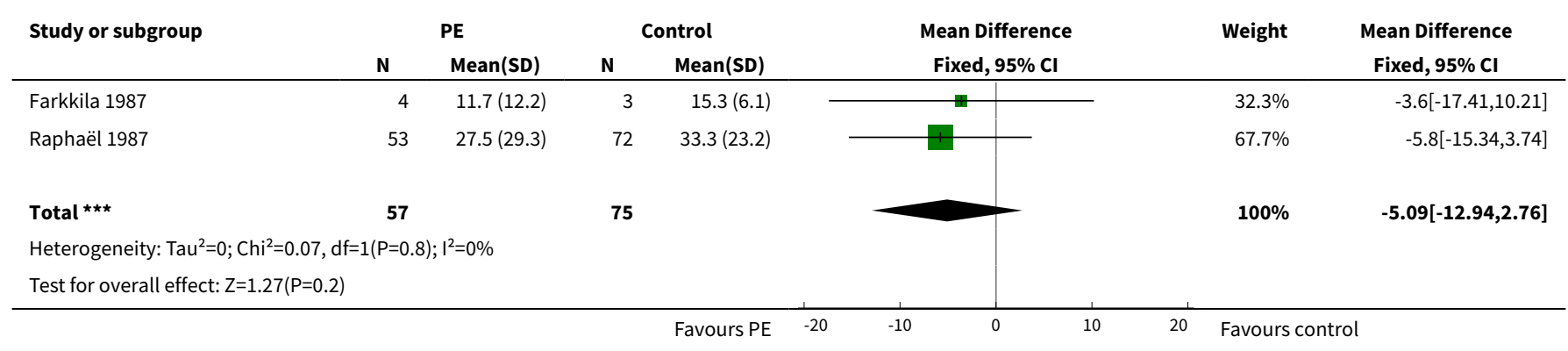

Comparison 2. Plasma exchange compared to sham exchange or supportive treatment for Guillain-Barré syndrome: one-year end points

\begin{tabular}{lllll}
\hline Outcome or subgroup title & No. of studies & $\begin{array}{l}\text { No. of partici- } \\
\text { pants }\end{array}$ & Statistical method & Effect size \\
\hline $\begin{array}{l}1 \text { Full muscle strength recov- } \\
\text { ery at 1 year }\end{array}$ & 5 & 404 & Risk Ratio (M-H, Fixed, 95\% Cl) & $1.24[1.07,1.45]$ \\
\hline 2 Deaths & 6 & 649 & Risk Ratio (M-H, Fixed, 95\% Cl) & $0.86[0.45,1.65]$ \\
\hline $\begin{array}{l}\text { 3 Severe motor sequelae } \\
\text { 4 Relapses during follow-up } \\
\text { period }\end{array}$ & 6 & 649 & Risk Ratio (M-H, Fixed, 95\% Cl) & $0.65[0.44,0.96]$ \\
\hline
\end{tabular}

Analysis 2.1. Comparison 2 Plasma exchange compared to sham exchange or supportive treatment for Guillain-Barré syndrome: one-year end points, Outcome 1 Full muscle strength recovery at 1 year.

\begin{tabular}{|c|c|c|c|c|c|}
\hline Study or subgroup & $\begin{array}{l}\mathrm{PE} \\
\mathrm{n} / \mathrm{N}\end{array}$ & $\begin{array}{c}\text { Control } \\
\mathrm{n} / \mathrm{N}\end{array}$ & $\begin{array}{c}\text { Risk Ratio } \\
\text { M-H, Fixed, 95\% Cl }\end{array}$ & Weight & $\begin{array}{c}\text { Risk Ratio } \\
\text { M-H, Fixed, 95\% Cl }\end{array}$ \\
\hline Farkkila 1987 & $12 / 13$ & $11 / 13$ & $\longrightarrow$ & $9.97 \%$ & $1.09[0.82,1.44]$ \\
\hline Greenwood 1984 & $4 / 14$ & $4 / 15$ & 1 & $3.5 \%$ & $1.07[0.33,3.48]$ \\
\hline
\end{tabular}




\begin{tabular}{|c|c|c|c|c|c|}
\hline Study or subgroup & $\begin{array}{l}\mathrm{PE} \\
\mathrm{n} / \mathrm{N}\end{array}$ & $\begin{array}{c}\text { Control } \\
n / N\end{array}$ & $\begin{array}{c}\text { Risk Ratio } \\
\text { M-H, Fixed, 95\% Cl }\end{array}$ & Weight & $\begin{array}{c}\text { Risk Ratio } \\
\text { M-H, Fixed, 95\% CI }\end{array}$ \\
\hline Osterman 1984 & $16 / 18$ & $15 / 20$ & $\longrightarrow$ & $12.89 \%$ & $1.19[0.88,1.6]$ \\
\hline Raphaël 1987 & $70 / 109$ & $57 / 111$ & 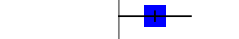 & $51.22 \%$ & $1.25[0.99,1.57]$ \\
\hline Raphaël 1997a & $33 / 45$ & $25 / 46$ & $\longrightarrow$ & $22.42 \%$ & $1.35[0.98,1.85]$ \\
\hline Total $(95 \% \mathrm{Cl})$ & 199 & 205 & & $100 \%$ & $1.24[1.07,1.45]$ \\
\hline \multicolumn{6}{|c|}{ Total events: 135 (PE), 112 (Control) } \\
\hline \multicolumn{6}{|c|}{ Heterogeneity: $\mathrm{Tau}^{2}=0 ; \mathrm{Chi}^{2}=1.24, \mathrm{df}=4(\mathrm{P}=0.87) ; \mathrm{I}^{2}=0 \%$} \\
\hline \multicolumn{6}{|c|}{ Test for overall effect: $Z=2.8(P=0.01)$} \\
\hline
\end{tabular}

Analysis 2.2. Comparison 2 Plasma exchange compared to sham exchange or supportive treatment for Guillain-Barré syndrome: one-year end points, Outcome 2 Deaths.

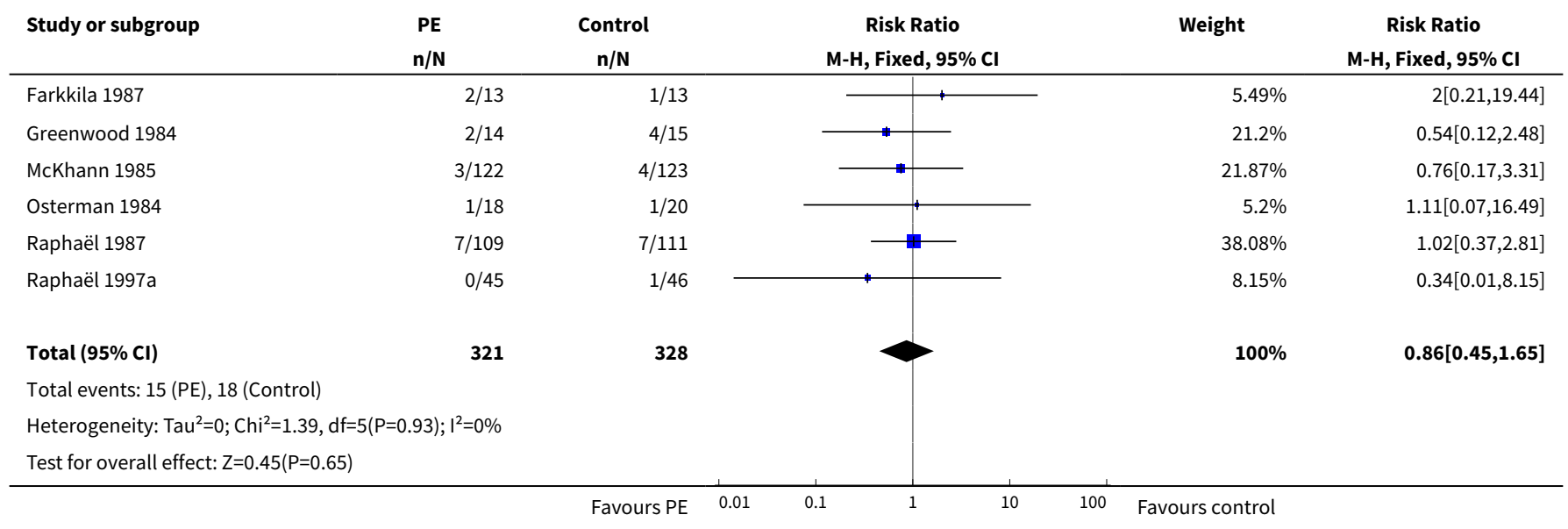

Analysis 2.3. Comparison 2 Plasma exchange compared to sham exchange or supportive treatment for Guillain-Barré syndrome: one-year end points, Outcome 3 Severe motor sequelae.

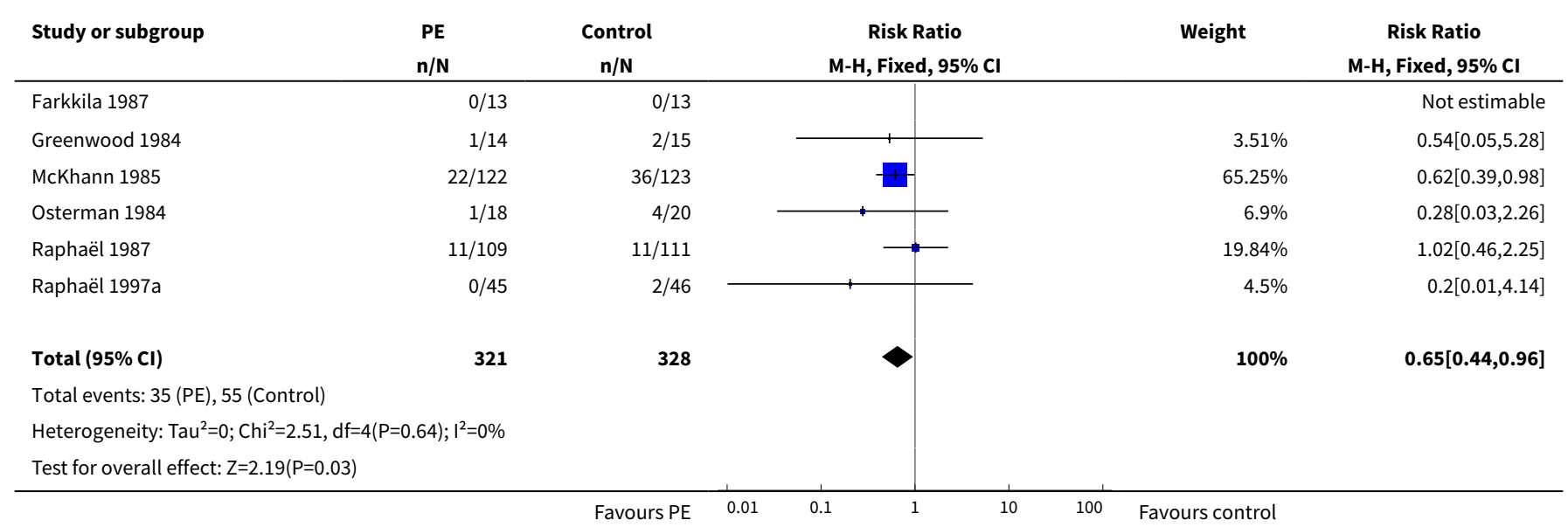


Analysis 2.4. Comparison 2 Plasma exchange compared to sham exchange or supportive treatment for Guillain-Barré syndrome: one-year end points, Outcome 4 Relapses during follow-up period.

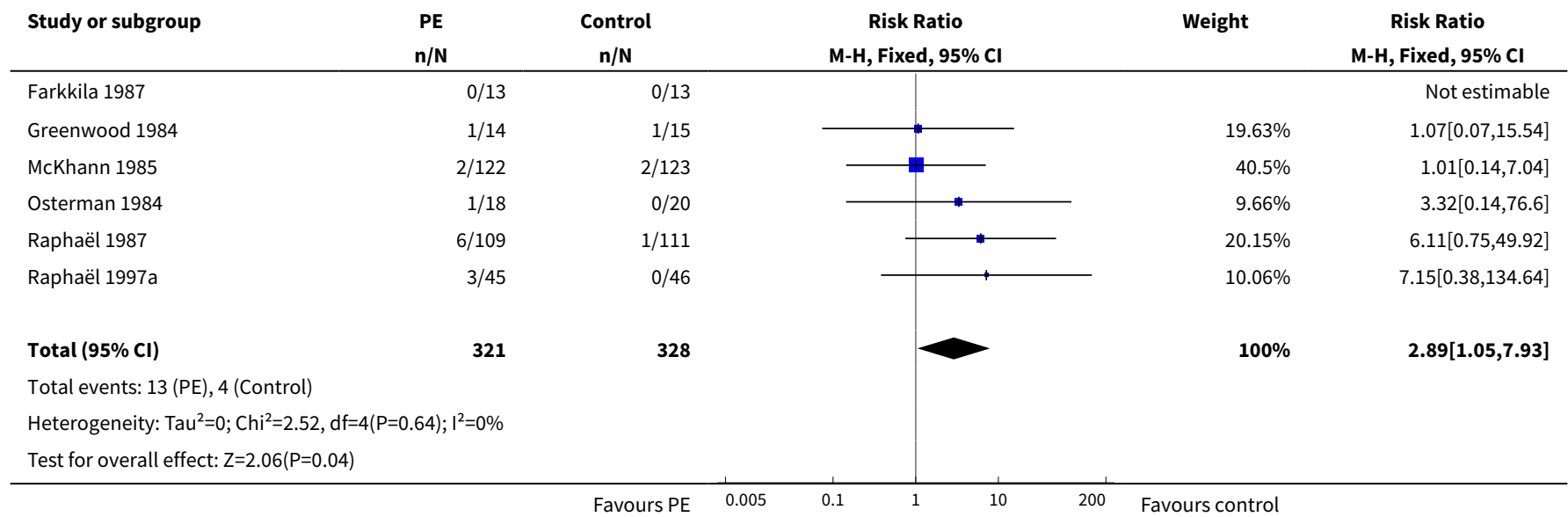

Comparison 3. Plasma exchange compared to sham exchange or supportive treatment for Guillain-Barré syndrome: complications during hospital stay

\begin{tabular}{llllll}
\hline Outcome or subgroup title & No. of studies & $\begin{array}{l}\text { No. of partici- } \\
\text { pants }\end{array}$ & Statistical method & Effect size \\
\hline 1 Severe infection & 3 & 556 & Risk Ratio (M-H, Fixed, 95\% Cl) & $0.91[0.73,1.13]$ \\
\hline 2 Blood pressure instability & 3 & 556 & Risk Ratio (M-H, Fixed, 95\% Cl) & $0.88[0.64,1.22]$ \\
\hline 3 Cardiac arrhythmias & 3 & 556 & Risk Ratio (M-H, Fixed, 95\% Cl) & $0.75[0.56,1.00]$ \\
\hline 4 Pulmonary embolus & 3 & 556 & Risk Ratio (M-H, Fixed, 95\% Cl) & $1.01[0.26,4.00]$ \\
\hline
\end{tabular}

Analysis 3.1. Comparison 3 Plasma exchange compared to sham exchange or supportive treatment for Guillain-Barré syndrome: complications during hospital stay, Outcome 1 Severe infection.

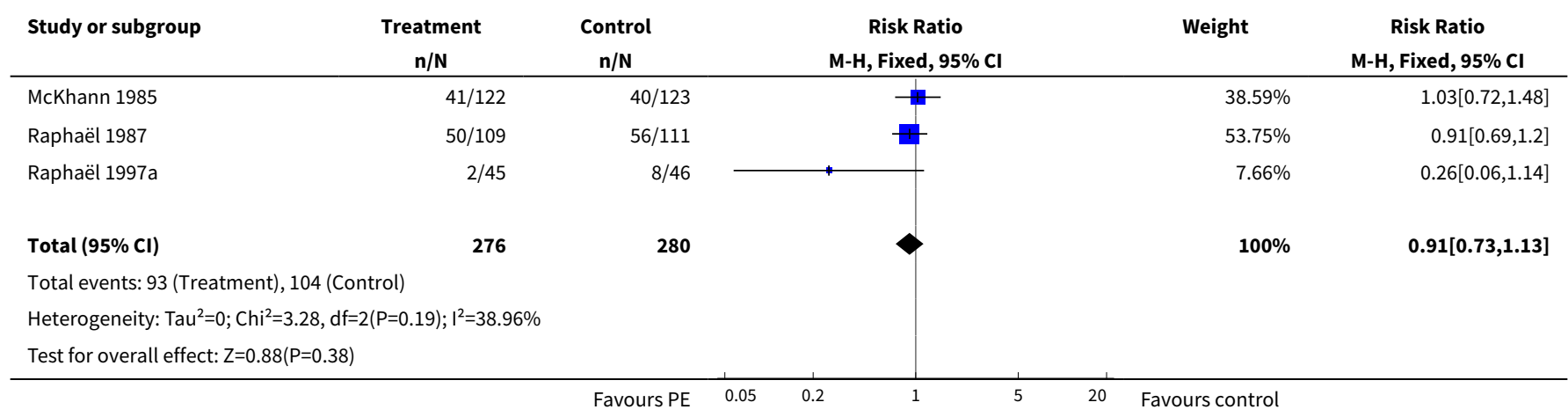


Analysis 3.2. Comparison 3 Plasma exchange compared to sham exchange or supportive treatment for Guillain-Barré syndrome: complications during hospital stay, Outcome 2 Blood pressure instability.

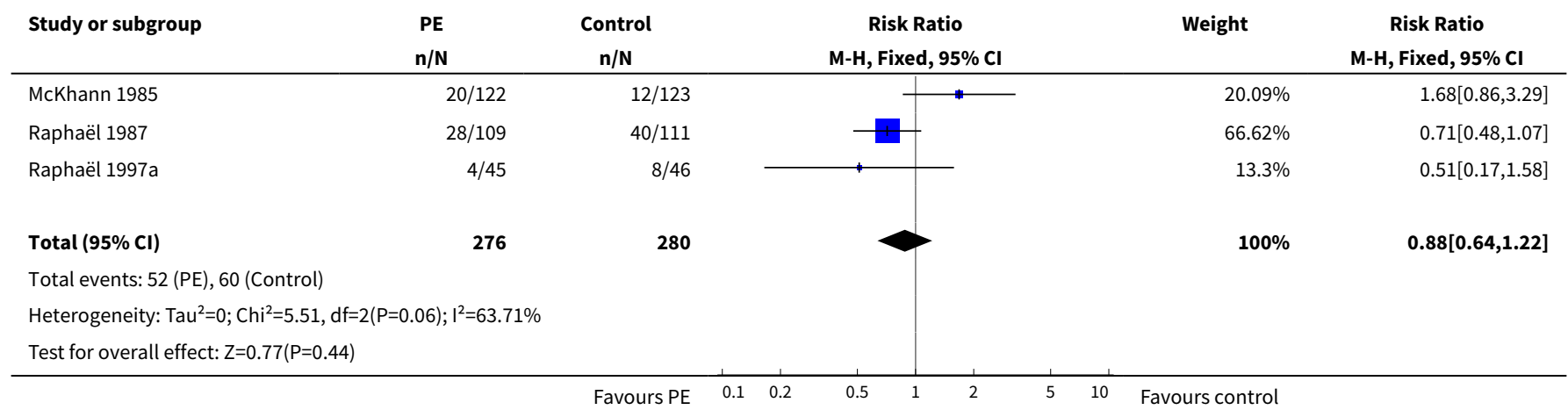

Analysis 3.3. Comparison 3 Plasma exchange compared to sham exchange or supportive treatment for Guillain-Barré syndrome: complications during hospital stay, Outcome 3 Cardiac arrhythmias.

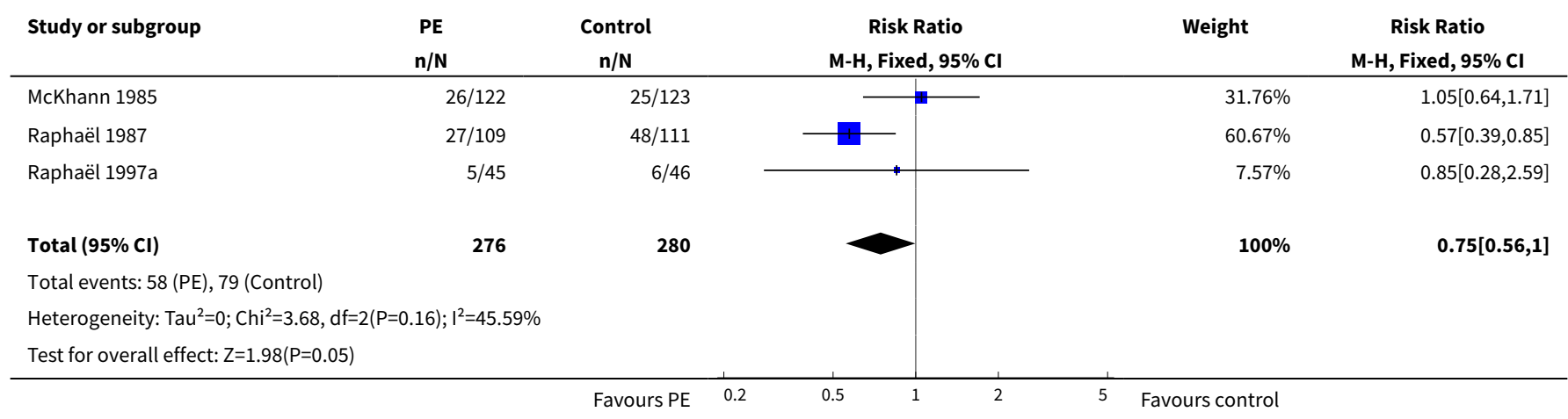

Analysis 3.4. Comparison 3 Plasma exchange compared to sham exchange or supportive treatment for Guillain-Barré syndrome: complications during hospital stay, Outcome 4 Pulmonary embolus.

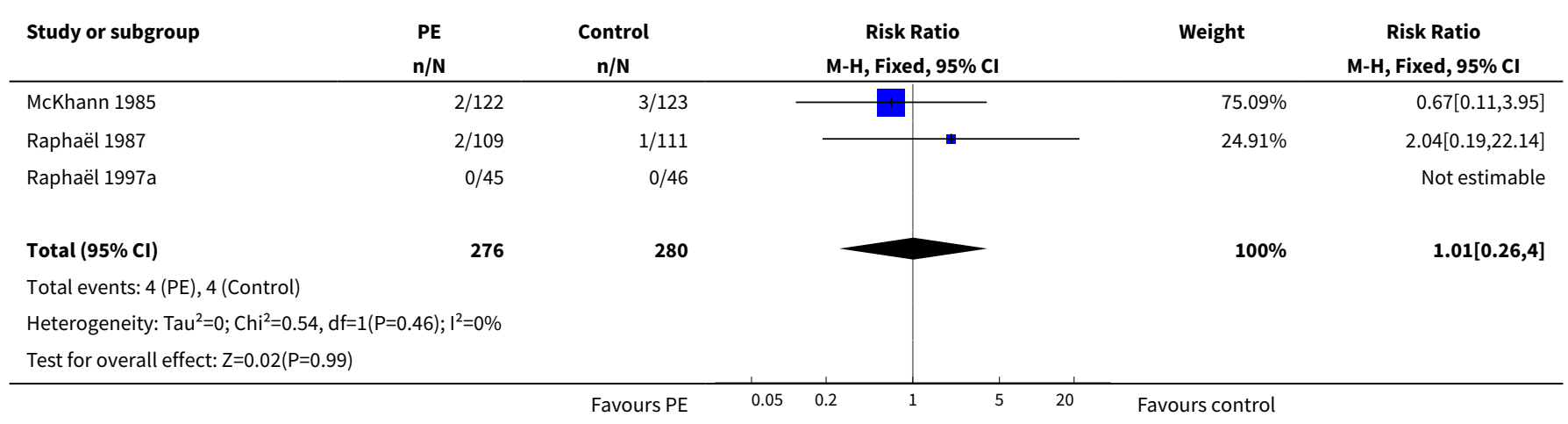




\section{APPENDICES}

\section{Appendix 1. Cochrane Neuromuscular Specialised Register (CRS) search strategy}

\#1 "guillain barre" [REFERENCE] [STANDARD]

\#2 MeSH DESCRIPTOR Polyradiculoneuropathy [REFERENCE] [STANDARD]

\#3 MeSH DESCRIPTOR Polyneuropathies [REFERENCE] [STANDARD]

\#4 "acute polyradiculoneuritis" or "acute polyneuritis" [REFERENCE] [STANDARD]

\#5 (inflammatory NEAR5 neuropathy) or (inflammatory NEAR5 neuropathies) [REFERENCE] [STANDARD]

\#6 (inflammatory NEAR5 polyneuropathy) or (inflammatory NEAR5 polyneuropathies) [REFERENCE] [STANDARD]

\#7 \#1 or \#2 or \#3 or \#4 or \#5 or \#6 [REFERENCE] [STANDARD]

\#8 "plasma exchange" or plasmapheresis [REFERENCE] [STANDARD]

\#9 \#7 and \#8 [REFERENCE] [STANDARD]

$\# 10$ (\#7 and \#8) AND (INREGISTER) [REFERENCE] [STANDARD]

\section{Appendix 2. The Cochrane Central Register of Controlled Trials (CRSO) search strategy}

\#1("guillain barre syndrome*"):TI,AB,KY

\#2MESH DESCRIPTOR Polyradiculoneuropathy

\#3MESH DESCRIPTOR Polyneuropathies

\#4("acute polyradiculoneuritis" or "acute polyneuritis"):TI,AB,KY

\#5(inflammatory NEAR polyneuropath ${ }^{\star}$ ):TI,AB,KY

\#6(inflammatory NEAR neuropath $\left.{ }^{\star}\right): \mathrm{TI}, \mathrm{AB}, \mathrm{KY}$

\#7\#1 OR \#2 OR \#3 OR \#4 OR \#5 or \#6

\#8"plasma exchange" or plasmapheresis

\#9\#7 AND \#8

\section{Appendix 3. MEDLINE (OvidSP) search strategy}

Database: Ovid MEDLINE(R) < 1946 to January Week 1 2016>

Search Strategy:

1 randomized controlled trial.pt. (403073)

2 controlled clinical trial.pt. (89915)

3 randomized.ab. (300387)

4 placebo.ab. (154014)

5 drug therapy.fs. (1808615)

6 randomly.ab. (212904)

7 trial.ab. (309257)

8 groups.ab. (1350141)

9 or/1-8 (3426105)

10 exp animals/ not humans.sh. (4171020)

119 not 10 (2916990)

12 guillain barre syndrome.tw. or Guillain-Barre Syndrome/ (7019)

13 polyradiculoneuropathy/ or polyneuropathies/ (8127)

14 (acute polyradiculoneuritis or acute polyneuritis).mp. (176)

15 (inflammatory adj5 neuropath\$3).tw. (1919)

16 (inflammatory adj5 polyneuropath\$3).tw. (1517)

17 or/12-16 (15117)

18 Plasma exchange.tw. or Plasma Exchange/ (7406)

19 plasmapheresis.tw. or plasmapheresis/ (10524)

2018 or 19 (16647)

2111 and 17 and 20 (339)

22 remove duplicates from 21 (331)

\section{Appendix 4. EMBASE (OvidSP) search strategy}

Database: Embase <1980 to 2016 Week 03>

Search Strategy:

1 crossover-procedure/ (45572)

2 double-blind procedure/ (125253)

3 randomized controlled trial/ (390064)

4 single-blind procedure/ (21312) 
5 (random\$ or factorial\$ or crossover\$ or cross over\$ or cross-over\$ or placebo\$ or (doubl\$ adj blind\$) or (singl\$ adj blind\$) or assign\$ or allocat\$ or volunteer\$).tw. (1539078)

6 or/1-5 (1621877)

7 exp animals/ (20581748)

8 exp humans/ (16523153)

97 not ( 7 and 8) (4058595)

106 not 9 (1465076)

11 limit 10 to embase (1203331)

12 guillain barre syndrome.tw. or Guillain Barre Syndrome/ (12977)

13 (acute polyradiculoneuritis or acute polyneuritis).mp. (188)

14 Polyneuropathies/ or Polyradiculoneuropathy/ (9902)

15 (inflammatory adj5 neuropath\$3).tw. (2986)

16 (inflammatory adj5 polyneuropath\$3).tw. (2377)

17 or/12-16 (24838)

18 Plasmapheresis/ or plasmapheresis.tw. (31307)

19 (plasma adj3 exchange).mp. (9945)

20 or/18-19 (33019)

2111 and 17 and 20 (216)

22 remove duplicates from 21 (216)

\section{Appendix 5. ClinicalTrials.gov search strategy}

Advanced search

Condition: Guillain Barre

Intervention: plasma exchange

\section{Appendix 6. WHO International Clinical Trials Registry Platform search strategy}

Basic search

guillain barre AND plasma Exchange

WHAT'S NEW

\begin{tabular}{lll}
\hline Date & Event & Description \\
\hline 17 March 2017 & Amended & $\begin{array}{l}\text { Correction to 'Summary of findings' table outcome 'Walking with } \\
\text { aid at 4 weeks' and removal of moderate risk from whole table. }\end{array}$ \\
\hline
\end{tabular}

\section{H I S T O R Y}

Protocol first published: Issue 3, 1999

Review first published: Issue 2, 2001

\begin{tabular}{lll}
\hline Date & Event & Description \\
\hline 20 January 2016 & New search has been performed & New search from 18 January 2016 incorporated \\
\hline 20 January 2016 & $\begin{array}{l}\text { New citation required but conclusions } \\
\text { have not changed }\end{array}$ & No new trials \\
\hline 30 March 2012 & $\begin{array}{l}\text { New citation required but conclusions } \\
\text { have not changed }\end{array}$ & $\begin{array}{l}\text { Updated searches were run to 14 June 2011. There were no new } \\
\text { randomised controlled trials }\end{array}$ \\
\hline 15 June 2011 & New search has been performed & $\begin{array}{l}\text { 'Risk of bias' tables and 'Summary of findings' tables have been } \\
\text { incorporated }\end{array}$ \\
\hline
\end{tabular}

Plasma exchange for Guillain-Barré syndrome (Review) 


\begin{tabular}{lll}
\hline Date & Event & Description \\
\hline 14 May 2008 & New search has been performed & Updated searches were run to January 2008. \\
\hline 15 April 2008 & Amended & Converted to new review format. \\
\hline 17 May 2006 & New search has been performed & $\begin{array}{l}\text { We updated the searches in 2006. We searched the Cochrane } \\
\text { Neuromuscular Disease Group specialised register (March 2006), } \\
\text { MEDLINE (to May 2006) and EMBASE (to May 2006). No new rele- } \\
\text { vant references were identified. }\end{array}$ \\
\hline 12 December 2001 & $\begin{array}{l}\text { New citation required and conclusions } \\
\text { have changed }\end{array}$ & $\begin{array}{l}\text { Substantive amendment } \\
\end{array}$ \\
\hline
\end{tabular}

\section{CONTRIBUTIONS OF AUTHORS}

DA and Jean Claude Raphaël (JCR) prepared the data extraction form for earlier versions of the review. JCR, DA, and SC extracted the data and wrote the first draft. RACH checked the data and edited the first and subsequent drafts. DA entered data onto the computer. All four authors agreed the final text. DA and RACH updated the review in 2001, 2004, 2006, and 2011. JCR died in February 2011. DA, RACH, and SC updated the review in 2016.

\section{DECLARATIONS OF INTEREST}

SC co-ordinated two RCTs that reported a beneficial effect. She has no known commercial conflicts of interest.

RACH holds or held consultancies with the following companies that produce IVIg or immunosuppressive drugs: CSL Behring, LFB, and Novartis. He participated in an RCT that did not report any beneficial effect and co-ordinated another that showed equivalent efficacy of plasma exchange and intravenous immunoglobulin (IVIg).

DA: no known conflicts of interest.

\section{SOURCES OF SUPPORT}

\section{Internal sources}

- Hopital Raymond Poincaré, Garches, France.

- Guy's, King's and St Thomas' School of Medicine, King's College, London, UK.

\section{External sources}

- No sources of support supplied

\section{DIFFERENCES BETWEEN PROTOCOLAND REVIEW}

We added 'Summary of findings' tables and revised the methods used to assess risk of bias in accordance with guidance in the 2011 Cochrane Handbook for Systematic Reviews of Interventions (Higgins 2011).

\section{NOTES}

New evidence on this topic is slow to emerge. The review will be assessed for updating in 2020.

\section{IN DEX TERMS}

\section{Medical Subject Headings (MeSH)}

*Plasma Exchange; Guillain-Barre Syndrome [immunology] ["therapy]; Muscle Strength; Randomized Controlled Trials as Topic; Recovery of Function; Recurrence; Treatment Outcome

\section{MeSH check words}

Humans 